\title{
An Ethnological Analogy and Biogenetic Model for Interpretation of Religion and Ritual in the Past
}

\author{
Michael James Winkelman ${ }^{1,2}$ (1)
}

Accepted: 18 March 2021/Published online: 30 April 2021

(C) The Author(s) 2021

\begin{abstract}
This paper provides a method- and theory-focused assessment of religious behavior based on cross-cultural research that provides an empirically derived model as a basis for making inferences about ritual practices in the past through an ethnological analogy. A review of previous research provides an etic typology of religious practitioners and identifies their characteristics, selection-function features, the societal configurations of practitioners, and the social complexity features of the societies where they are found. New analyses reported here identify social predictors of the individual practitioner types in their relationships to subsistence and sociopolitical conditions (foraging, intensive agriculture, political integration, warfare, and community integration). These relations reveal the factors contributing to social evolution through roles of religious organization in the operation of cultural institutions. The discussion expands on the previous findings identifying fundamental forms of religious life in the relations of the selection processes for religious practitioner positions to their principal professional functions. These relationships reveal three biogenetic structures of religious life involving (1) alterations of consciousness used in healing rituals, manifested in a cultural universal of shamanistic healers; (2) kin inheritance of leadership roles providing a hierarchical political organization of agricultural societies, manifested in priests who carry out collective rituals for agricultural abundance and propitiation of common deities; and (3) attribution of evil activities, manifested in witches who are persecuted and killed in subordinated groups of societies with political hierarchies and warfare. These systematic cross-cultural patterns of types of ritualists and their activities provide a basis for inferring biogenetic bases of religion and models for interpreting the activities, organization, and beliefs regarding religious activities of past societies. Cases are analyzed to illustrate the utility of the models presented.
\end{abstract}

Keywords Religion · Shaman · Priest · Cross-cultural research · Ethnographic analogy · Cultural evolution of religion

Retired

Michael James Winkelman

Extended author information available on the last page of the article 


\section{Introduction: Cross-cultural Research as a Basis for Archaeological Inference}

Evidence of ritual and religious practices in the archaeological record or historical accounts raise questions as to the nature of the activities involved and the characteristics of the practitioners. However physical the artifacts of this past religious behavior might be, direct information regarding the nature of the ritual practices and the characteristics of the functionaries involved is generally limited. An ethnographic analogy is normally used, where artifacts and practices from a current or historical culture provide a model for interpreting something from past. But as Ember and Ember (1995) pointed out, the archaeological practice of reliance on inferences from ethnographic analogy faces numerous sources of possible error and no systematic way to determine their validity or accuracy. Peregrine (2004) shows that in contrast to ethnographic analogies, models derived from cross-cultural approaches can provide archaeology with reliable frameworks for constructing ethnological analogies regarding the institutions and practices of cultures of the past. Cross-cultural patterns can inform archaeological inference, providing a basis from which to generalize about societal types, infer causes of phenomena, attribute interpretations to material findings, and make inferences about diverse cultural practices of the past based on associations found in worldwide data. Comparative ethnology can provide models that allow artifactual remains (i.e., settlement and dwelling size) be used to interpret populations features such as sedentary lifestyle, marital residence, marriage patterns, kinship and social organization, warfare, political hierarchy, and even religious practices (also see Václav et al., 2020; Kahn, 2015).

The significance of cross-cultural research for establishing causal relationships between social and religious variables is illustrated by Whitehouse et al. (2019) who use global longitudinal data to address the "moralizing gods" hypothesis, that "morally concerned supernatural agents culturally evolved to facilitate cooperation among strangers in large-scale societies [and] . . . may help to sustain and expand complex multi-ethnic empires." These functional effects of religious beliefs in providing adaptations in complex societies are complemented here by research which focuses on behavior, rather than belief, and provides a focus on what Boyer $(2019$, p. 1) called "wild religions ... the forms of religious activity that occurred before the emergence of state societies and doctrinal religious organizations." The present paper presents ethnological analogies derived from studies of such societies that can provide information regarding the characteristics of religious behaviors of partially known cultures through identification of systematic cross-cultural patterns of religion of the past.

\section{Projecting Religion into the Past: the Case of Shamanism}

So what can be reliably inferred about religious practices in the past? A classic ethnographic analogy has been the hunter-gatherer band, but loose ethnographic analogies, rather than models derived from systematic cross-cultural research have neglected variation in hunter-gatherer groups (Kelly, 2013). In anthropological accounts of band societies, a consistent religious form has been recognized - shamanism. But affluent hunter-gatherer societies produce a more complex social dynamic with non-egalitarian social structures, wars, and slaves (Kelly, 2013). These affluent huntergatherer societies produce a new form of religious activity characterized by large-scale 
monumental architecture and other features (see Hayden, 2003) which supplement shamanism with new forms of religious activity represented in some societies in the role of priests.

If religious activity of the past is assumed to be shamanism, just what is shamanism? Conjectures are often based on arbitrary definitions rather than derived from ethnology (cross-cultural research). The attribution of other religious statuses such as priests is often made, especially for large-scale societies, but the nature of the practitioners and their activities also involve inferences that lack a basis in systematic cross-cultural research.

The notion of distinctly different types of religious practitioners is nonetheless implicit in academic studies of religion. Scholars often refer to shamans, healers, medicine men, prophets, priests, and witches in a way that implicitly assumes that there are both central distinctions among these types, as well as some fundamental cross-cultural similarity to each of these types of practitioners. But exactly what is common to all the practitioners of a given type is underspecified, and generally not empirically informed by systematic cross-cultural research.

Problems related to imposed or presumed etic concepts in the anthropology of religion are most apparent in the use of the concept of shaman, where a term with widespread cognates in Paleosiberian languages was adopted into Western academic discourse as a presumably cross-culturally valid concept. The term shaman was subsequently extended to refer to spiritual and religious practitioners across time and cultures, from the Paleolithic era to a diversity of contemporary spiritual healing practices.

This kind of use of the term shaman is problematic. Some (Eliade, 1964; Hultkrantz, 1973) explicitly stated what they viewed as the commonalities of shamans worldwide but used impressionistic assessments rather than systematic research to establish the communalities they presumed to exist. Many who purport the validity of a crosscultural concept of shamanism have used a selective and haphazard synthesis of ethnographic data (e.g., Lewis-Williams, 2002) to produce a loose ethnographic analogy or employ an arbitrary definitional approach (e.g., see Jakobsen, 1999). The use of arbitrary definitions produces widely varying concepts of shamans, for instance some applying it to any practitioner that alters consciousness (e.g., Peters \& Price-Williams, 1981), while others propose restriction of the term to practitioners from the Paleosiberian regions from which the word was borrowed (e.g., Siikala, 1978). Still others propose definitions that include or exclude concepts such as soul flight, spirit possession, or sorcery without any empirical basis to justify the inclusion or exclusion of specific features.

The failure to use ethnological models and the persistence of arbitrary definitions even appear in prominent archaeological publications on shamanism that claim to use concepts of shamans based on ethnological evidence. For instance, in "The signs of the sacred: Identifying shamans using archaeological evidence," VanPool (2009, p. 177) asserts a basis for shamanism in "a robust empirical pattern initially identified by ethnologists" but does not cite any ethnologists nor present what that "robust empirical pattern" actually is. The irony is that VanPool then cites Jones (2008), asserting that he has "validated the etic category of shamanism, defined as individual, part-time practitioners who commune with spirits (Jones, 2008)" (VanPool, 2009, p. 177). But Jones is not someone who has researched the etic concept of shamanism, but rather someone 
who rejects the idea rather than validating it. Neither the phrase "commune with spirits" nor even the word "spirits" which VanPool offers as an etic definition in citing Jones appears anywhere at all in Jones' text. Furthermore, Jones offers a very different definition than VanPool attributes to him: "the following preliminary nominal definition of the phenomenon of shamanism . . . is a phenomenon consisting of an individual who has voluntary access to, and control of, more aspects of their consciousness than other individuals" (Jones, 2008, p. 21). Such a definition does not sufficiently characterize shamans, nor differentiate shamans from mystics, mediums, healers, meditators, and many others who access different aspects of consciousness; instead, it typifies the inherent problems in simplistic definitional approaches.

And in contrast to VanPool's allegation that Jones "validated the etic category of shamanism," Jones does not even present or endorse some ethnological approach or etic concept of the shaman. His considerations are focused on North America and he directly rejects any etic or cross-cultural concept of shamanism. "The current study of the phenomenon defined by these terms [shamanism and shaman] consequently has become extremely loose and nonsensical" (p. 20) "[C]urrent definitions of shamanism work only in particular spatiotemporal contexts, and . . . these definitions cannot be used . . . in conjunction with the spatiotemporally free cross-cultural and neurophenomenological theories" (Jones p. 22). Jones certainly does not agree with an etic concept of shamanism as VanPool asserts.

In Figure 1 of her article, VanPool alleges a series of traits associated with shamans versus priest but offers no source of evidence why such traits should be considered at all, much less with respect to one type or the other. While VanPool alleges "well established worldwide shamanic patterns" presented in Figure 1 of her article, they are not referenced to any ethnological studies that establish such features. Furthermore, without presenting any cross-cultural evidence, the list includes (see p. 179) such questionable "shamanic" features as pilgrimages and processions, star gazing, and short periods of apprenticeship; and denies characteristics such as formalized regalia and long periods of training. In spite of claims regarding "robust empirical pattern initially identified by ethnologists" and the "well established worldwide shamanic patterns," VanPool provides no references to systematic cross-cultural research that establishes the patterns asserted in the article.

Most who use the term shaman for inferences regarding the past use some loose ethnographic analogy to select the features they attribute; consequently, the features selected and the types of religious practitioners considered have extreme diversity. To establish the legitimacy of such terms, we need cross-cultural research, without which we cannot empirically resolve questions regarding the cross-cultural validity of religious practitioner types, or indeed the universality of any religious impulse. On the other hand, cross-cultural research described below provides powerful methodological tools aiding in the development of empirically grounded theory for the interpretation of archaeological findings and making inferences about ritual practices of the past.

\section{Previous Research Findings}

This paper first reviews the materials and methods of the author's previous ethnological research (Winkelman, 1985, partially reported in 1986a, 1990) that analyzed 
descriptive data (rather than imposing arbitrary definitions or a priori concept) to obtain a derived etic model of religious practitioners. The categories (religious types) derived from these prior analyses and the features of each type of religious practitioner are presented in new table formats that emphasize the comparative differences among religious practitioners rather than just their features. Previous analyses are summarized that reveal the different configurations of religious practitioners found in simple and complex societies that indicate a general evolutionary model; this model is further articulated in the new analyses.

The societal functional dynamics of these practitioners are characterized with the findings of relationships between the processes used for selection of individuals for the religious practitioner role and the practitioners' professional role activities (functions). Since these religious practitioners represent in many cases the most significant leaders of pre-modern societies, the procedures by which they are selected are key to explaining the roles of religious organization in societal functions and political evolution. The relationship between these selection procedures and the social-religious functions that the practitioners provide with their rituals reveals relationships that constitute fundamental forms (structures) of religion and society.

How one acquires the position of religious practitioners involves three basic processes: spontaneous and deliberate experiences (alterations of consciousness) that are considered profoundly religious, and frequently induced through stressful procedures that epitomize costly rituals; social inheritance of positions that approximate primogeniture at the highest levels of leadership positions in society; and social ascription by religious leaders of immoral behavior to accused persons, justifying extreme persecution of the accused.

\section{New Analyses and Findings}

The section of the paper below entitled "New Findings: Subsistence and Socio-political Predictors of Religious Practitioner Types" provides new analyses of the sociocultural evolution of religious practitioners with updated assessments of the relationships of subsistence and sociopolitical variables to these practitioner types. These features are proposed to identify the causal factors involved in the transformation and emergence of different types of religious practices across sociocultural evolution. The new analyses identifying the different social variables predicting the various practitioner types are shown to have direct relationships to the distinctive characteristics of different practitioner types, illustrating the effects of sociocultural evolution on religious institutions and practices and producing the distinctive characteristics of the types (i.e., Foraging Shaman versus Agricultural Shaman differences related to effects of agriculture on society).

These biogenetic bases revealed in relationships of selection processes and professional functions are discussed in light of more recent research to explain how innate dispositions underlying religious sentiments and practices change as a function of subsistence, social organization, and political institutions. Combined with the subsistence and social variables associated with each religious type, this ethnological analogy provides a biosocial paradigm that enables well-based inferences about past religious activities that exceeds the power of ethnographic analogy. 


\section{Materials and Methods}

This cross-cultural research on types of religious practitioners was a dissertation (Winkelman, 1985) partially summarized in articles (Winkelman, 1986a, b, 1990) and an out-of-print monograph (Winkelman, 1992); a revised dataset is available (Winkelman \& White, 1987; also see author's research projects page at www. researchgate.net or Mendeley data repository at https:/data.mendeley.com/datasets/ $34 \mathrm{pjbr} 4 \mathrm{~kg} 4 / 2$ ). The types of religious practitioners presented here are based on that previous research, with the current report presenting new analyses of their social predictors based on the Standard Cross-Cultural Sample (SCCS) data in the online CosSci ${ }^{1}$ database.

The 47 -society sample ${ }^{2}$ used is a $26 \%$ subsample of the SCCS (Murdock \& White, 1969); it was derived by selecting the first and then every fourth society of the SCCS as the subsample. Since the order of societies represents geographical proximity, this subsample is representative of regional variation in the SCCS. Two of the societies, the Hadza and the Tuehueleche, lacked published information on religion, and were replaced by societies in their respective region (!Kung Bushmen and Mapuche, respectively).

\section{Behaviorally Grounded Assessments: Practitioner Statuses and Roles}

The first unit of coding was not the society per se, but each of the religious statuses or positions recognized within the society and the roles and characteristics associated with those occupying each of these professions. The study first assessed ethnographic reports to individually characterize each of the society's recognized types of religious professionals with coded variables. The socially recognized religious professionals analyzed here were thought by their society to have a special capacity for interacting with supernatural beings or supernatural power, typically involving someone who underwent special training in order to function in a socially recognized role relating to the supernatural.

\section{Determination of Practitioners}

What constituted a religious practitioner was generally not problematic. The ethnographers often presented the practitioners using presumed etic terms (i.e., healer, witch, shaman, priest), as well as the indigenous word expressing the society's conceptual framework (see Winkelman, 1990, 1992, Appendix 1). Excluded were healers whose cultures did not consider their ability to be related to supernatural power.

\footnotetext{
${ }^{1}$ CosSci is a program housed at the University of California, Irvine, that provides provides an online format for analyses of data coded for the Standard Cross-cultural Sample; see http://socscicompute.ss.uci.edu/. This program was made accessible by Doug White.

${ }^{2}$ Societies in the sample and their respective regions included Africa-Nama Hottentot, Kung Bushmen, Ovimbundu, Mbuti, Ibo; Circum-Mediterranean-Wolof, Fulani, Fur, Kafa, Amhara, Tuareg, Babylonians, Romans, Kurd; Eurasia-Samoyed (Yurak), Toda, Kazak, Garo, Vietnamese, Semang, Tanala, Japanese, Chukchee; Insular Pacific_-Iban, Alor, Kimam, Lesu, Bunlap (Pentecost), Marquesans, Trukese, Atayal; North America-Montagnias, Kaska, Twana, Wadadokado (Paiute), Hidatsa, Creek, Zuni, Aztec; South America-Bribri, Callinago, Saramacca, Jivaro, Siriono, Tupinamba, Cayua, Mapuche
} 
These religious professions performed a variety of rituals, private and public. The data analyses presented here focus on these professionals with specialized religious abilities, not the magical and religious activities available to the general populace. They did include some practitioners who were attributed the status and activities (i.e., causing illness and death) to which they generally did not admit. The unit of coding was a culturally recognized professional, with three exceptions. Two of the societies in this subsample (Mbuti and Siriono) lacked altogether religious practitioners, the focus of this study. These two hunter-gatherer societies had undergone extensive deculturation and/or depopulation. Lacking professional religious practitioners, they were coded on the following: their collective ritual activities led by men's society (molirao of Mbuti); and the supernatural abilities generally available to members of the society (Siriono). While this non-professional data from the Mbuti and Siriono were included in exploratory analyses, they were excluded in the final cluster analyses because they distorted the solutions. Nonetheless, the Mbuti and Siriono codes for general magico-religious activities are included in the data reported (Winkelman \& White, 1987) and are available in the CosSci data base used in new analyses reported here ${ }^{3}$. The Roman ancestor worship was also included for exploratory purposes. The Roman paterfamilias, head of family, who carried out ancestor worship, was not technically a magicoreligious practitioner as construed here because he was not a specialized professional but engaged in a familial activity performed by all heads of household. It was included here to determine the relationship of ancestor worship to the practitioner types.

In some cultures, the religious practitioners had highly specialized practices, where some practitioners of a type provided services not provided by other practitioners of the same type. One case is the Trukese sourooor where individual practitioners may specialize in agricultural rituals or divination or healing or even malevolent activities, but not all of these. These different specializations of a religious practitioner status were considered in the same type or as different types on the basis of selection and training characteristics. They were coded as a single specialized practitioner type if the selection and training characteristics were the same for all specializations, but if the different specializations had different selection and training processes, they were coded as separate practitioners (i.e., the Tanala ombiasy nkazo versus ombiasy manangatra).

\section{Coding of Religious Practitioner Types}

Each of the culturally recognized religious practitioners was individually coded with a standard format characterizing the practitioners' reported features. The format was revised reiteratively in the early stages of the project to obtain a set of variables that reflected the characteristics that ethnographers reported for the practitioners. Variables were also refined to exclude those for which information was not regularly found (i.e., the various concepts of types of souls). The practitioners were assessed across a broad range of areas, including selection procedures for the profession; their social and economic class; their sociopolitical powers and activities; training conditions; the

\footnotetext{
3 These non-practitioner cases are represented in the CosSci program in a category of the Healer variable (v881.d2), a subtype of the religious practitioner type they most closely resembled in cluster analyses. Three additional religious practitioners (from the Wolof, Kazak, Bunlap/Pentecost) not covered in the initial coding, but discovered during the subsequent code check phase, are also classified in this Healer category on the basis of their key features rather than the cluster analyses.
} 
nature of professional activities, covering worship and propitiation, types of healing and divination, malevolent acts, and seasonal rites; sources of supernatural power, including spiritual, personal, and impersonal (i.e., mana); the nature of the practitioner's relationships to spirits; their psychological, social, and economic characteristics; life cycle rituals; the nature of their practitioner organizations; the social context of their professional services; and ritual practices for altering consciousness and their characteristics (see Winkelman, 1985 for analyzed variables or footnote for update ${ }^{4}$ ).

\section{Results}

The practitioner types previously identified by the cluster analyses described below provided the basis for several areas of analysis that establish ethnological analogies for archaeological interpretations in identifying:

Etic types of religious practitioners and their respective characteristics;

Their configurations of co-occurrence of practitioner types; and

The relationships of selection procedures and training to professional functions.

The new analyses reported here update the previously reported relationships of each religious practitioner type to subsistence and sociopolitical conditions, providing more complete models of their societal determinants. The relationships of practitioner types to subsistence and sociopolitical conditions reveal a general cultural evolutionary and presumably the factors responsible for development and transformation of the different types of religious practitioners. These findings are integrated with a discussion of differences among practitioner types that illustrate the effects of subsistence and social conditions on the cultural evolution of religious institutions.

\section{Previous Findings: a Derived Etic Model of Religious Practitioner Types}

The original variables were reduced to 98 measurements (because of SPSS variable limits at the time) and cluster analyses solutions were determined with a variety of measurement conditions. The similarities among cases were assessed with Gower's Coefficient (Gower, 1971), which combines nominal, ordinal, and interval levels of measurement into a single matrix of similarities.

Single, average, and complete link assessments of similarities among practitioners were examined to determine stable group (cluster) assignments across different measurement conditions. Although differences exist among the various cluster analysis solutions, most practitioner cases were classified in the same grouping across different amalgamation procedures, with only approximately $10 \%$ of the 115 cases shifting between groups across solutions. The non-practitioner cases (Mbuti and Siriono) were eliminated after exploratory analyses since their inclusion distorted solutions in forming

\footnotetext{
${ }^{4}$ For updated variables, values, variable descriptions, coding instructions, and data, see Winkelman and White (1987); the author's page at www.researchgate.net and https:/www.researchgate.net/project/Magico-religiousPractitioners; or the Mendeley data repository at https:/data.mendeley.com/datasets/34pjbr4kg4/2.
} 
early nodes that increased the number of inconsistently classified cases. Cluster analysis solutions (reported in Winkelman, 1985) used in the final analyses employed the mixed-variables condition, which is designed to reduce the effect of missing data, since they generated larger and more distinctly separated clusters. The solutions used to classify practitioners into types were the average and complete link solutions. Classification of inconsistently grouped practitioners was resolved by the following: (1) categorizing them with the group with which they were most consistently clustered; and (2) creating an intermediate group (type) with cases inconsistently clustered between two groups (see Shaman/Healers below).

\section{Typology of Religious Practitioners}

These etic types of religious practitioners identified through empirical analysis have been labeled with common terms frequently used to refer to the typical different types of religious practitioners:

\section{Healer Complex:}

(a) Shaman (Forager Shaman)

(b) Shaman/Healer (Agricultural Shaman)

(c) Healer

2. Medium

3. Priest

4. Sorcerer/Witch

These types of religious practitioners are the variables analyzed below (CosSci SCCS variable numbers in parentheses): Shaman (v879), Shaman/Healer (v880), Healer (v881), Medium (v882), Sorcerer/Witch (v883), and Priest (v884). In the following, these variables (i.e., Shamans $=\mathrm{v} 879$ ) are referred to with initial capitalized letters, while lowercase initial letters are used for discussing general concepts (i.e., shamans, priests, healers, etc.). The same convention is used in referring to other SCCS variables, including the CosSci SCCS variable number in the initial presentation of the variable (i.e., Political Integration v157); the extensions (i.e., d345) refer to the variable values (categories) collapsed into binary recodes.

These classifications were verified (Winkelman, 1985) with the BMDP KMeans procedure (Dixon \& Brown, 1979) that reassigned 14 cases (11\% of the sample), primarily reflecting inconsistencies across clustering solutions involving the practitioners of the Healer Complex. This typology was further validated by the average link amalgamations which showed discontinuity after 4 groups, combined with complete link solutions that indicate discontinuity after 6 groups. This justifies representing 4 major types, with one type divided into three subgroups for a total of 6 groups. These two different levels of discontinuity reflect the variable clustering of some cases with the Healer or Shaman group under different amalgamation rules; these inconsistently classified cases were resolved by creating an intermediate group, the Shaman/Healers. This subdivision was further justified by methodological and theoretical interests in determining factors responsible for the transformation of the Shamans, with these inconsistently 
classified cases identifying a transitional group represented in Shaman/Healers. External validation of these types of practitioners is provided by the analyses below which show the following: their exclusion relationships among the types at the societal level; and the strong prediction of these practitioner types by subsistence and political conditions.

\section{Characteristics of Religious Practitioner Types}

The variables used in cluster analyses to determine the empirical typology of religious practitioners were assessed for each type, with the frequency and percentage of these variables for each type of practitioner used to determine their typical features. The data in Tables 1, 2, and 3 present these basic features of each practitioner type to provide information identifying the roles and activities that typify each type. The characteristics of the types reveal cross-cultural patterns of religious behavior that can be used to validly infer activities of practitioners and their practices in the past, using additional information provided below on the social conditions associated with each practitioner type.

These features reported in Tables 1,2, and 3 were not necessarily reported for every case of the type but the features reported for each type were either (1) present in at least two-thirds $(67 \%)$ of the cases of the practitioner type and the data quality measures providing missing data assessments had significant negative correlations with the coding for the variable, indicating its absence was associated with low quality of reporting; or (2) the frequency of the variable for the religious practitioner type constituted at least $50 \%$ of the incidence of that variable value across all practitioner types, indicating that the variable was most typically associated with that specific practitioner type. More detailed descriptions of these etic religious practitioners derived from the formal cross-cultural research are available here (Winkelman, 1985, 1990, 1992, 2010a).

\section{Religious Practitioner Configurations}

The results from the cluster analysis - a typology of religious practitioners - were subsequently aggregated at the societal level to discover the relationships among these practitioners and their social predictors. The number of types of religious practitioners present showed several typical patterns across societies which were discovered with entailment analyses, using the religious practitioner type data aggregated at the societal level (Winkelman, 1986a). The major dynamic is the contrast between the Shaman and the Priest, who have exclusion relations - they do not occur together in the same society. Furthermore, the Shamans have exclusion relationships with all other types of religious practitioners as well, meaning that if a Shaman is present, generally there are no other types of religious practitioners in the society (2 exceptions). The Priests, in contrast, are entailed by all other types of religious practitioners except Shamans - if a Shaman/Healer, Healer, Medium, or Sorcerer/Witch is present in a society, then there is a Priest present as well. Mediums also entail Healers - if there is a Medium present then there generally is a Healer present as well. It should be noted that the causal implication is the opposite of the entailment: a Priest is necessary for the presence of a Shaman/ Healer, Healer, Medium, and Sorcerer/Witch. The co-relationships among practitioners 
Table 1 Characteristics of religious practitioner types with regard to selection training, selection training, motive and context, and supernatural power/control of power

\begin{tabular}{|c|c|c|c|c|}
\hline $\begin{array}{l}\text { Religious } \\
\text { practitioner } \\
\text { type }\end{array}$ & Selection training & $\begin{array}{l}\text { Magico- } \\
\text { eligious activity }\end{array}$ & Motive and context & $\begin{array}{l}\text { Supernatural } \\
\text { power/control of } \\
\text { power }\end{array}$ \\
\hline $\begin{array}{l}\text { Shaman } \\
\text { (Forager } \\
\text { Shaman) }\end{array}$ & $\begin{array}{l}\text { Dreams, illness, and } \\
\text { sings of spirit's } \\
\text { request } \\
\text { ASC induction, } \\
\text { normally vision } \\
\text { quest by individual } \\
\text { practitioner alone in } \\
\text { wilderness }\end{array}$ & $\begin{array}{l}\text { Healing and divination } \\
\text { Protection from spirits } \\
\text { and malevolent } \\
\text { magic } \\
\text { Hunting magic } \\
\text { Malevolent } \\
\text { magic-caused } \\
\text { illness and death }\end{array}$ & $\begin{array}{l}\text { Acts at client request } \\
\text { for client, } \\
\text { local community } \\
\text { Community } \\
\text { ceremony at night }\end{array}$ & $\begin{array}{l}\text { Animal spirits, } \\
\text { spirit allies } \\
\text { Spirit power usually } \\
\text { controlled }\end{array}$ \\
\hline $\begin{array}{c}\text { Shaman/Healer } \\
\text { (Agricultural } \\
\text { Shaman) }\end{array}$ & $\begin{array}{l}\text { Vision quest, dreams, } \\
\text { illness and spirit } \\
\text { requests } \\
\text { ASC and ritual } \\
\text { training by group } \\
\text { Ceremony recognizes } \\
\text { status }\end{array}$ & $\begin{array}{l}\text { Healing and divination } \\
\text { Protection against } \\
\text { spirits and } \\
\text { malevolent magic } \\
\text { Hunting magic and } \\
\text { agricultural rites } \\
\text { Minor malevolent acts }\end{array}$ & $\begin{array}{l}\text { Acts at client request } \\
\text { Performance in } \\
\text { client group }\end{array}$ & $\begin{array}{l}\text { Animal spirit allies } \\
\text { and impersonal } \\
\text { power (mana) } \\
\text { Power controlled }\end{array}$ \\
\hline Healer & $\begin{array}{l}\text { Voluntary selection, } \\
\text { large payments to } \\
\text { trainer } \\
\text { Learn rituals and } \\
\text { techniques } \\
\text { Ceremony } \\
\text { recognizes status }\end{array}$ & $\begin{array}{l}\text { Healing and divination } \\
\text { Agricultural and } \\
\text { socioeconomic rites } \\
\text { Propitiation }\end{array}$ & $\begin{array}{l}\text { Acts at client request } \\
\text { in client group } \\
\text { Participates in } \\
\text { collective rituals } \\
\text { with Priests } \\
\text { Both client family } \\
\text { group and public } \\
\text { contexts }\end{array}$ & $\begin{array}{l}\text { Superior gods and } \\
\text { impersonal } \\
\text { power (mana) } \\
\text { Ritual techniques } \\
\text { and formulas } \\
\text { Propitiation and } \\
\text { command of } \\
\text { spirits }\end{array}$ \\
\hline Medium & $\begin{array}{l}\text { Spontaneous } \\
\text { possession by spirit } \\
\text { Training in } \\
\text { practitioner group } \\
\text { Ceremony } \\
\text { recognizes status }\end{array}$ & $\begin{array}{l}\text { Healing and divination } \\
\text { Protection from spirits } \\
\text { and malevolent } \\
\text { magic } \\
\text { Agricultural rituals } \\
\text { Propitiation }\end{array}$ & $\begin{array}{l}\text { Acts primarily for } \\
\text { clients at client } \\
\text { residence } \\
\text { Participates in public } \\
\text { ceremonies }\end{array}$ & $\begin{array}{l}\text { Possessing spirits } \\
\text { dominate } \\
\text { Power out of } \\
\text { control, } \\
\text { unconscious }\end{array}$ \\
\hline Priest & $\begin{array}{l}\text { Social inheritance or } \\
\text { succession } \\
\text { Political action } \\
\text { Incidental training } \\
\text { and/or by group } \\
\text { Ceremony recognizes } \\
\text { status. }\end{array}$ & $\begin{array}{l}\text { Protection and } \\
\text { purification } \\
\text { Agricultural planting } \\
\text { and harvest rites } \\
\text { Socioeconomic rites } \\
\text { Propitiation and } \\
\text { worship }\end{array}$ & $\begin{array}{l}\text { Acts to fulfill social } \\
\text { functions, } \\
\text { calendrical rites } \\
\text { Public rituals }\end{array}$ & $\begin{array}{l}\text { Power from } \\
\text { ancestors, } \\
\text { superior spirits, } \\
\text { or gods } \\
\text { Also have } \\
\text { impersonal } \\
\text { power and ritual } \\
\text { knowledge } \\
\text { No control over } \\
\text { spirit power }\end{array}$ \\
\hline Sorcerer/Witch & $\begin{array}{l}\text { Social labeling, } \\
\text { attribution of } \\
\text { biological } \\
\text { inheritance } \\
\text { Innate abilities, } \\
\text { self-taught or } \\
\text { learned }\end{array}$ & $\begin{array}{l}\text { Malevolent acts } \\
\text { Kill kin, cause illness, } \\
\text { death, economic } \\
\text { destruction }\end{array}$ & $\begin{array}{l}\text { Acts at client's } \\
\text { request or for } \\
\text { personal reasons } \\
\text { such as envy, } \\
\text { anger, jealousy, } \\
\text { greed, or revenge } \\
\text { Practices in secrecy }\end{array}$ & $\begin{array}{l}\text { Power from spirits } \\
\text { and ritual } \\
\text { knowledge } \\
\text { Power may be } \\
\text { unconscious/out } \\
\text { of control }\end{array}$ \\
\hline
\end{tabular}


Table 2 Characteristics of religious practitioner types with regard to social characteristics, sociopolitical power, professional characteristics, and ritual techniques

\begin{tabular}{|c|c|c|c|c|}
\hline $\begin{array}{l}\text { Religious } \\
\text { practitioner type }\end{array}$ & Social characteristics & Sociopolitical power & $\begin{array}{l}\text { Professional } \\
\text { characteristics }\end{array}$ & $\begin{array}{l}\text { Ritual } \\
\text { techniques }\end{array}$ \\
\hline $\begin{array}{l}\text { Shaman (Forager } \\
\text { Shaman) }\end{array}$ & $\begin{array}{l}\text { Predominantly male, } \\
\text { female secondary } \\
\text { High social status } \\
\text { Ambiguous moral } \\
\text { status }\end{array}$ & $\begin{array}{l}\text { Charismatic leader, } \\
\text { communal and war } \\
\text { leader } \\
\text { Makes witchcraft } \\
\text { accusations }\end{array}$ & $\begin{array}{l}\text { Part time } \\
\text { No group-individual } \\
\text { practice with } \\
\text { community } \\
\text { Status recognized by } \\
\text { clients }\end{array}$ & $\begin{array}{l}\text { Control of } \\
\text { spirits } \\
\text { Transformation } \\
\text { into animal }\end{array}$ \\
\hline $\begin{array}{l}\text { Shaman/Healer } \\
\text { (Agricultural } \\
\text { Shaman) }\end{array}$ & $\begin{array}{l}\text { Predominantly male } \\
\text { Moderate } \\
\text { socioeconomic } \\
\text { status } \\
\text { Predominantly moral } \\
\text { status }\end{array}$ & $\begin{array}{l}\text { Informal political } \\
\text { power } \\
\text { Moderate judiciary } \\
\text { decisions }\end{array}$ & $\begin{array}{l}\text { Part-time } \\
\text { Collective/group } \\
\text { practice, } \\
\text { joint ceremonies } \\
\text { Specialized role }\end{array}$ & $\begin{array}{l}\text { Spirit control, } \\
\text { spells, } \\
\text { charms, } \\
\text { exuvial and } \\
\text { imitative }\end{array}$ \\
\hline Healer & $\begin{array}{l}\text { Predominantly male, } \\
\text { female rare } \\
\text { High socioeconomic } \\
\text { status } \\
\text { Predominantly moral } \\
\text { status }\end{array}$ & $\begin{array}{l}\text { Judicial, legislative, } \\
\text { and economic } \\
\text { power } \\
\text { Life cycle rituals }\end{array}$ & $\begin{array}{l}\text { Full-time } \\
\text { Collective training, } \\
\text { practice, } \\
\text { and ceremony } \\
\text { Highly specialized } \\
\text { role }\end{array}$ & $\begin{array}{l}\text { Charms, spells, } \\
\text { rituals, } \\
\text { and sacrifice }\end{array}$ \\
\hline Medium & $\begin{array}{l}\text { Predominantly } \\
\text { female; male } \\
\text { secondary/rare. } \\
\text { Low socioeconomic } \\
\text { status. } \\
\text { Exclusively moral. }\end{array}$ & $\begin{array}{l}\text { Informal political } \\
\text { power. } \\
\text { May designate who } \\
\text { are sorcerers and } \\
\text { witches. }\end{array}$ & $\begin{array}{l}\text { Part-time. } \\
\text { Collective/group } \\
\text { practice }\end{array}$ & $\begin{array}{l}\text { Propitiation and } \\
\text { sacrifices }\end{array}$ \\
\hline Priest & $\begin{array}{l}\text { Exclusively male } \\
\text { High social and } \\
\text { economic status } \\
\text { Exclusively moral }\end{array}$ & $\begin{array}{l}\text { Political, legislative, } \\
\text { judicial, economic, } \\
\text { and military power }\end{array}$ & $\begin{array}{l}\text { Full-time } \\
\text { Hierarchically } \\
\text { organized } \\
\text { practitioner group }\end{array}$ & $\begin{array}{l}\text { Propitiation and } \\
\text { sacrifices }\end{array}$ \\
\hline Sorcerer/Witch & $\begin{array}{l}\text { Male and female } \\
\text { Low social and } \\
\text { economic status } \\
\text { Exclusively immoral }\end{array}$ & None & $\begin{array}{l}\text { Part-time } \\
\text { Little or no } \\
\text { professional } \\
\text { organization } \\
\text { May be killed }\end{array}$ & $\begin{array}{l}\text { Contagious, } \\
\text { exuvial, } \\
\text { imitative } \\
\text { magic, spells }\end{array}$ \\
\hline
\end{tabular}

as a function of the number of types of practitioners found in a society are illustrated in Fig. 1.

\section{Selection-Function Relations of Religious Practitioners}

The cross-cultural distribution of these patterns of institutionalized types of religious practitioners suggests that there are underlying dispositions leading to the same fundamental forms of religious life being manifested across cultures. In order to identify the underlying biogenetic functions, entailment analyses were used to identify the relationship between the processes for practitioner selection and the formal functions (activities) of the religious practitioner type (Winkelman, 1985; also see Winkelman, 1986a, 1992 for details). This revealed three chains of implicative structures where 
Table 3 Characteristics of religious practitioner types with regard to ASC conditions and labels, ASC techniques and characteristics, and healing concepts and practices

\begin{tabular}{|c|c|c|c|}
\hline $\begin{array}{l}\text { Religious } \\
\text { practitioner } \\
\text { type }\end{array}$ & $\begin{array}{l}\text { ASC conditions } \\
\text { and labels }\end{array}$ & $\begin{array}{l}\text { ASC techniques } \\
\text { and characteristics }\end{array}$ & $\begin{array}{l}\text { Healing concepts and } \\
\text { practices }\end{array}$ \\
\hline $\begin{array}{l}\text { Shaman } \\
\text { (Forager } \\
\text { Shaman) }\end{array}$ & $\begin{array}{l}\text { ASC in training and practice } \\
\text { Soul flight/journey; } \\
\text { death-and-rebirth, } \\
\text { animal transformation }\end{array}$ & $\begin{array}{l}\text { Isolation, austerities, fasting, } \\
\text { entheogens, chanting, } \\
\text { singing, drumming and } \\
\text { dancing and frequently } \\
\text { collapse and apparent } \\
\text { unconsciousness }\end{array}$ & $\begin{array}{l}\text { Soul loss, spirit aggression, } \\
\text { sorcery } \\
\text { Physical manipulations, } \\
\text { sucking, blowing and } \\
\text { massaging and extraction } \\
\text { Plant medicines }\end{array}$ \\
\hline $\begin{array}{l}\text { Shaman/Healer } \\
\text { (Agricultural } \\
\text { Shaman) }\end{array}$ & $\begin{array}{l}\text { ASC in training and practice } \\
\text { Shamanic and mystical } \\
\text { ASC Occasionally soul } \\
\text { flight, animal } \\
\text { transformation }\end{array}$ & $\begin{array}{l}\text { Isolation, austerities, fasting, } \\
\text { chanting, singing, } \\
\text { percussion, and } \\
\text { collapse/unconsciousness }\end{array}$ & $\begin{array}{l}\text { Extraction and exorcism, } \\
\text { spirit aggression } \\
\text { Physical manipulations, } \\
\text { massaging and extraction } \\
\text { Plant medicines, cleanse } \\
\text { wounds }\end{array}$ \\
\hline Healer & $\begin{array}{l}\text { ASC induction limited or } \\
\text { absent } \\
\text { No apparent ASC }\end{array}$ & $\begin{array}{l}\text { Social isolation; fasting; } \\
\text { minor austerities; } \\
\text { limited singing, chanting, } \\
\text { or percussion }\end{array}$ & $\begin{array}{l}\text { Exorcism and prevent illness } \\
\text { Physical manipulation of } \\
\text { body, empirical medicine, } \\
\text { imitative and exuvial } \\
\text { techniques }\end{array}$ \\
\hline Medium & $\begin{array}{l}\text { ASC in training and practice } \\
\text { Possession ASC }\end{array}$ & $\begin{array}{l}\text { ASC induced through } \\
\text { singing, drumming, } \\
\text { dancing Tremors, } \\
\text { convulsions, seizures, } \\
\text { compulsive motor } \\
\text { behavior, amnesia, } \\
\text { dissociation }\end{array}$ & $\begin{array}{l}\text { Possession and exorcisms } \\
\text { Control of possessing spirits }\end{array}$ \\
\hline Priest & $\begin{array}{l}\text { Generally no ASC apparent } \\
\text { or very limited }\end{array}$ & $\begin{array}{l}\text { Occasionally alcohol } \\
\text { consumption, sexual } \\
\text { abstinence, } \\
\text { social isolation, and sleep } \\
\text { deprivation }\end{array}$ & $\begin{array}{l}\text { Purification and protection } \\
\text { Public rituals and sacrifices }\end{array}$ \\
\hline Sorcerer/Witch & $\begin{array}{l}\text { Indirect evidence of ASC } \\
\text { Flight and animal } \\
\text { transformation }\end{array}$ & Nighttime activities & $\begin{array}{l}\text { Illness caused by } \\
\text { consumption of victim's } \\
\text { soul, spirit aggression, } \\
\text { magical darts that enter } \\
\text { victim, unconscious } \\
\text { emotional effects of envy, } \\
\text { anger, etc. }\end{array}$ \\
\hline
\end{tabular}

selection processes entail functions, rather than vice versa indicating that there is a causal relationship of the selection processes to professional activities.

1. Alteration of consciousness and healing.

If the practitioner is selected for the role based on:

(a) Experiencing signs from the spirits, involuntary illness or spontaneous visions, then 


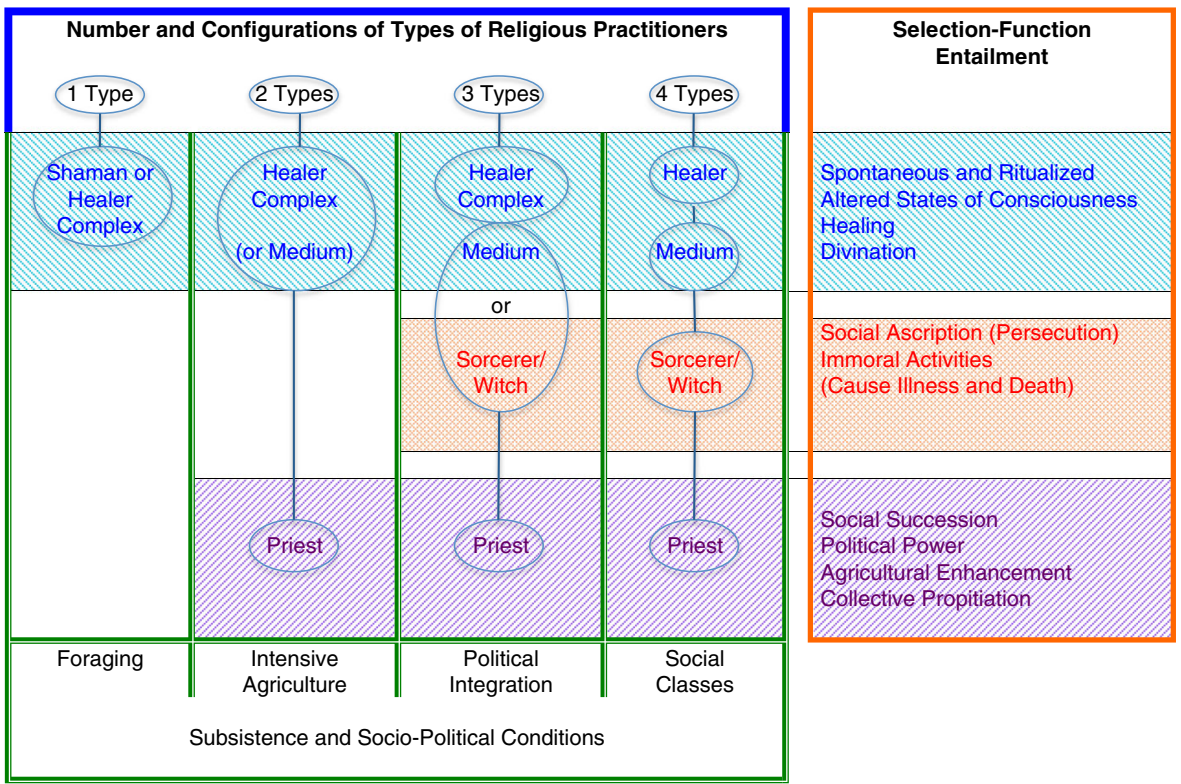

Fig. 1 Configurations of religious practitioner types, selection-function relationships, and social complexity

(b) The practitioner undergoes training involving ritual alterations of consciousness and

(c) Engages in professional activities involving healing and divination.

These selection-function relations are typical of the practitioners of the Healer Complex (all Shamans and Shaman/Healers and some of Healers) and all of the Mediums. All societies have religious practitioners involving ritual induction of altered states of consciousness as a basis for professional activities involving healing and divination; Winkelman $(1990,1992)$ proposed the term shamanistic healers to encompass religious practitioners with these characteristics.

2. Political succession and agricultural propitiation

If the religious practitioner was selected for the position through processes:

(a) Involving some form of social succession (typically father to son) or some form of political action (i.e., political negotiations or war); then

(b) The practitioner exercises a variety of political powers (warfare, legislative, and judicial); and

(c) Has primary functions involving seasonal ceremonies related to agricultural fertility (especially planting and harvest) and performs rituals of collective propitiation for obtaining protection from high gods.

These selection-function relations were characteristic of the Priests, the pre-eminent social leader who performs seasonal ceremonies related to agricultural fertility and the collective propitiation of deities and typified what is generally considered to be religion. 
3. Social ascription and malevolence

If the religious practitioner was selected on the basis of:

(a) Negative social labeling or other forms of unwanted attribution of the status or activities, then;

(b) The activities of the practitioner are malevolent and alleged to involve immoral acts (such as causing illness, death, destruction of crops, and other forms of misfortune).

These features were characteristic of the practitioners labeled Sorcerer/Witches. The immoral activities attributed are such core characteristics of Sorcerer/Witches that they are generally conceptualized as such an antithesis of religion that they are not even considered in many characterizations of the scope of religious behavior.

\section{Sociopolitical Predictors of Practitioner Configurations}

These configurations of practitioner types are strongly correlated with subsistence and socio-political conditions (Winkelman, 1986a). A Religious Practitioner Configurations variable representing the four categories of practitioner configurations (1-4 Types) depicted in Fig. 1 was screened against the SCCS Social Complexity variables (CosSci v149-v158, Murdock \& Provost, 1973), with the variables with significant correlations entered into an autocorrelation multiple regression analysis. The independently significant variables were the following: Agriculture (v151) as a major means of subsistence; Political Integration (beyond the local community) (v157d345); and Social Stratification (classes or castes, v158d345). They had a large multiple $\mathrm{r}\left(\mathrm{R}=.82, \mathrm{r}^{2}=.68, p<.001\right)$ and no evidence of diffusion effects (see Winkelman, 1986a, 1992 for further details).

This simplistic compilation of the data does not capture all the complexity of these configurations of practitioner types, but the autocorrelation analyses indicate these practitioner configurations resulted independently and related to the effects of agriculture, political integration, and social stratification. Additional new analyses are reported next to explain how subsistence and political processes have effects on the cultural evolution of religion by identifying the variables which significantly predict the societal incidence of the individual religious practitioner types.

\section{New Findings: Subsistence and Sociopolitical Predictors of Religious Practitioner Types}

In order to identify the processes responsible for the emergence, cultural evolution, and transformation of religious practitioner types, this section presents new analyses of the subsistence, social, and political predictors of the individual types of religious practitioners, updating the predictors previously reported (Winkelman, 1985, 1986a, 1990) with additional analyses recently performed with the CosSci program (see footnote 1). The variables selected for analysis were as follows: more sensitive measures of subsistence than used in the initial analyses, emphasizing foraging measures and varying degrees of agriculture; judiciary and community complexity; and political measures, especially warfare variables. These later 
variables were recommended by Doug White as important predictors of social change and were designed to help elucidate the processes underlying the significant correlations with political integration and social stratification found in the overall initial analyses. The significant findings from the final models are presented below in Table 4; full regressions results are available at the author's page on researchgate.net ${ }^{5}$.

\section{Societal Predictors of Shamans}

Previously reported analyses of the relationship of the incidence of Shamans with respect to social complexity measures found independently significant predictors with binary recodes of an absence of Political Integration (beyond the level of the local community) and nomadic or semi-nomadic lifestyle (Fixity of Residence v150d12). This relationship is replicated here in initial analyses with independently significant correlations (multiple $\mathrm{R}^{2}=.40$ ). Since nomadic or sedentary lifestyle is not likely a causal factor in and of itself, but rather reflects other factors that permit or impose a sedentary lifestyle (i.e., agriculture), it was removed from the regression equation to permit identification of more likely causal factors.

Relationships of social conditions to the incidence of Shamans were assessed with a series of exploratory correlational analyses with subsistence and social and political variables to identify the most significant predictors. These were confirmed in a regression analysis with:

1. A measure of Overall Foraging based on a summation of the overall contributions to subsistence of Gathering (v203), Hunting (v204), and Fishing (v205);

2. A binary recode for Intensive Agriculture (v151d5); and

3. The Frequency of External Warfare (v1747).

All were individually significant, the latter two with negative correlations, and with substantial increases in explained variance over the previous model (multiple $\mathrm{R}^{2}=.56$ ). Additional variables (i.e., measures of nomadism/sedentarism, community administration, political integration, judiciary and political complexity) had significant correlations but were not independently significant in multiple regression, nor did their inclusion increase explained variance.

These new analyses clarify that the presence of shamanism is maintained not by nomadism per se, but by the effects of a lifestyle based on foraging activities (hunting, gathering, and fishing), and by the lack of intensive agriculture and the lack of external warfare. Characterized conversely, the decline in foraging activities, the adoption of intensive agriculture, and the incidence of external warfare result in the demise of archaic shamanism manifested in the Shaman or Forager Shaman. Further analyses below of the social predictors of the Shaman/Healer (and Shaman and Shaman/Healer combined) reveal that political integration is also a central factor in the transformation and demise of Shamans.

\footnotetext{
${ }^{5}$ https:/www.researchgate.net/project/Magico-religious-Practitioners/update/5fa6bf42828e0b0001610e0b\% 2D\%2D Project ->Magico-religious Practitioners->Project log $\rightarrow$ Regression Tables
} 
Table 4 Subsistence and sociopolitical conditions predicting magico-religious practitioners

\begin{tabular}{|c|c|c|c|}
\hline Independent variable and significant predictors & Coefficient & Standardized coefficient & $* p<$ \\
\hline \multicolumn{4}{|l|}{ Sorcerer/Witch, $\mathrm{MR}^{2}=.62$} \\
\hline Intercept & -0.1084 & NA & 0.6152 \\
\hline Political Integration & 0.2772 & 0.2860 & 0.0766 \\
\hline Intensive Agriculture & 0.2907 & 0.2712 & 0.0486 \\
\hline Community Integration & -0.0619 & -0.1975 & 0.0409 \\
\hline Judiciary & 0.1860 & 0.4356 & 0.0092 \\
\hline \multicolumn{4}{|l|}{ Priest, $\mathrm{MR}^{2}=.63$} \\
\hline Intercept & 0.0719 & NA & 0.7526 \\
\hline Intensive Agriculture & 0.0907 & 0.2822 & 0.0177 \\
\hline Political Integration & 0.6427 & 0.6511 & 0.0000 \\
\hline \multicolumn{4}{|l|}{ Shamanistic Healers, $\mathrm{MR}^{2}=.52$} \\
\hline Intercept & -0.7432 & NA & 0.6189 \\
\hline Political Integration & 0.9766 & 0.2478 & 0.0817 \\
\hline War-Nonland Resources & 0.2466 & 0.2114 & 0.0315 \\
\hline Overall Foraging & -0.1683 & -0.2687 & 0.0273 \\
\hline \multicolumn{4}{|l|}{ Medium, $\mathrm{MR}^{2}=.52$} \\
\hline Intercept & -0.4626 & NA & 0.0001 \\
\hline Political Integration & 0.4906 & 0.5076 & 0.0000 \\
\hline Warfare-Plunder, Captives & 0.2690 & 0.2572 & 0.0079 \\
\hline \multicolumn{4}{|l|}{ Healer, $\mathrm{MR}^{2}=.49$} \\
\hline Intercept & -1.0233 & NA & 0.0225 \\
\hline Political Integration & 0.5670 & 0.5867 & 0.0040 \\
\hline War-Non-land Resources & 0.1135 & 0.3996 & 0.0018 \\
\hline Jurisdictional Hierarchy & -0.1573 & -0.4303 & 0.0389 \\
\hline Fixity of Settlement & 0.0952 & 0.3993 & 0.0164 \\
\hline Community Size & -0.0921 & -0.3626 & 0.0534 \\
\hline Community Integration & 0.1114 & 0.3670 & 0.0050 \\
\hline \multicolumn{4}{|l|}{ Shaman/Healer, $\mathrm{MR}^{2}=.39$} \\
\hline Intercept & 0.3982 & NA & 0.0987 \\
\hline Political Integration & -0.2689 & -0.3158 & 0.0392 \\
\hline Overall Foraging & -0.2823 & -0.2624 & 0.0234 \\
\hline Intensive Agriculture & 0.4980 & 0.5379 & 0.0005 \\
\hline \multicolumn{4}{|l|}{ Shaman $\mathrm{MR}^{2}=.56$} \\
\hline Intercept & 0.0878 & NA & 0.4960 \\
\hline External Warfare & -0.0764 & -0.2368 & 0.0438 \\
\hline Intensive Agriculture & -0.1929 & -0.1972 & 0.0174 \\
\hline Overall Foraging & 0.0576 & 0.4030 & 0.0066 \\
\hline
\end{tabular}

$* p=.1$ to remove 


\section{Societal Predictors of Shaman/Healers}

The original research found Shaman/Healers were significantly and independently correlated only with Agriculture. Current analyses with CosSci confirmed this correlation with Agriculture and found additional predictors through multiple regression analysis; the best model was with binary recodes for Overall Foraging (v246d123, negative correlation); supra-community Political Integration (negative correlation); and Intensive Agriculture (positive correlation), all with independently significant correlations (multiple $\mathrm{R}^{2}=.39$ ). However, there were no independently significant increases in explained variance from the addition of other political hierarchy, community, warfare, and sedentism measures.

The central role of political integration in processes leading to the transformation of both Shamans and Shaman/Healers was confirmed in (unreported) analyses with dummy variable representing them both (v879+v880), which has significant correlations with a variety of agricultural and warfare measures. But the only independently significant (negative) correlation in multiple regression was with Political Integration beyond the local community $\left(\mathrm{R}^{2}=.38\right)$; no significant increases in explained variance resulted from adding subsistence and various social complexity and warfare variables to the regression model.

The Shaman/Healers' negative correlation with Overall Foraging and Political Integration beyond the local community and positive correlation with Intensive Agriculture complement the variables predicting the incidence of Shamans, who are predicted by an Overall Foraging lifestyle and the lack of Intensive Agriculture.

\section{Societal Predictors of Healers}

The original research found Political Integration significantly predicts the Healer, as do Agriculture and Social Stratification, but only Political Integration was significant in multiple regression. The new CosSci multiple regression analyses of the Healer variable again found significant correlations (Multiple $\mathrm{R}^{2}=.49$ ) with positive correlations with Political Integration, Overall War for Non-land Resources (v1660), the degree of Community Integration (v73), and sedentary lifestyle (Fixity of Settlement, v61); and significant negative correlations with the extent of Jurisdictional Hierarchy (v237) and overall Community Size (v63).

\section{Societal Predictors of Mediums}

The original research found Mediums significantly predicted only by Political Integration beyond the local community ( $\mathrm{d} 345, \mathrm{r}=.51$ ). This relationship is confirmed here (multiple $\mathrm{R}^{2}=.46$ ), but there were no significant additional contributions to the regression from the other social complexity measures (Murdock \& Provost, 1973). The new analyses discovered that a warfare measure, Plunder Including Captives for Slaves and Adoption (v912), was also individually significant and in multiple regression with Political Integration (multiple $\mathrm{R}^{2}=.52$ ).

This re-confirmation of the significant prediction of Mediums by Political Integration provides more support for its fundamental role in the transformation of shamanism. Mediums' positive correlation complements the significant negative 
correlations of Shamans and Shaman/Healers with Political Integration. The additional significant prediction of Mediums by a measure of warfare involving Plunder is consistent with theories about the origination of Mediums' alterations of consciousness in trauma (Winkelman, 2018) such as that caused by taking women as captives for slaves and wives. This variable captures the dynamics of abuse and oppression thought to produce the dissociation and possession experiences typical of Mediums; however, a variety of measures that might directly represent nutritional deprivation and abuse of women (resource inadequacy, starvation, slavery, male dominance, and polygyny) did not contribute significantly to this regression model.

The Mediums were clustered as a practitioner type apart from the Healer Complex, amalgamating with them only after the clustering of the Shamans and Shaman/ Healers with the Healers. This indicates separate origins of the mediumistic traditions in a different cultural tradition and milieu than that which gave origin to shamanism. This is indicated in both their distinctive subsistence and political contexts (foraging vs politically integrated agricultural societies, respectively).

\section{Shamans and Shamanistic Healers: an Evolutionary Transformation}

The sequential social evolutionary relationship of Shamans followed by Shaman/ Healers and then Healers is attested to by several findings. First, cluster analyses grouped Shaman/Healers with either the Shamans or Healers in different solutions, showing they represent an intermediary form between the other two types. Secondly, these three forms of shamanistic healers have exclusion relationships, which is to say that do not co-occur in a given society (1 exception each), but they all share the same selection-function relations (alterations of consciousness for healing and divination). This shows that they are different forms of the same underlying religious basis. The sequential relation is also attested to by their differential relationships to social variables (Overall Foraging versus Intensive Agriculture versus Political Integration beyond level of local community). Of the 10 social complexity variables originally examined and the many other social and political measures studied here, it is noteworthy that the level of Political Integration is a significant predictor of all shamanistic healers (Shaman/ Healers, Shamans and Shaman/Healers combined, Healers, and Mediums), as well as Priests and Sorcerer/Witches (see below).

To determine if there are other conditions contributing to this cultural evolution, a variable-Shamanistic Healers - was created as follows to represent their sequential relationship as an ordinal 6-point scale (values in parentheses):

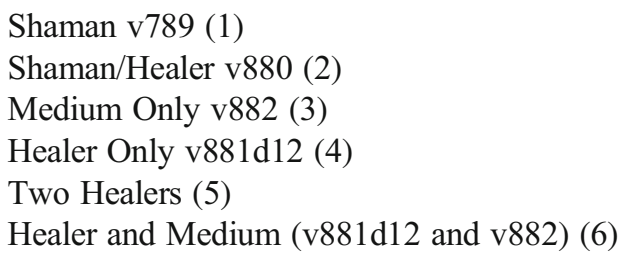

This scale incorporated the Mediums because of their shared functional characteristics with the Healer Complex: the presence of selection and training involving alterations of 
consciousness and the performance of divination and healing rituals. Mediums were found in all of the societies where the Healer Complex practitioners were absent and fulfilled these same functions.

This scale of Shamanistic Healers was significantly correlated with a variety of subsistence, political, and community complexity variables, with the best model from Political Integration, Plunder (warfare), and the computed measure of Overall Foraging (multiple $\mathrm{R}^{2}=.52$ ). Similar contributions to explained variance were obtained with substituting Community Integration for Political Integration, but neither was significant with both in the equation. This summary analysis confirms factors identified in analyses of the individual shamanistic healers, implicating subsistence change (foraging to intensive agriculture transition) and political processes (political integration and warfare) as central to the processes transforming religious bases originally manifested in shamanism.

\section{Societal Predictors of Priests}

The original research found Priests significantly predicted by Agriculture, Political Integration (beyond the local community), and Social Stratification (classes or castes), with all but the last variable independently significant (multiple $r=.70$ ). The current analyses found similar results: Political Integration and Agriculture were individually and collectively significant (multiple $\mathrm{R}^{2}=.63$ ). Inclusion of a variety of social complexity, jurisdictional, community, and culture change variables did not significantly increase explained variance.

\section{Societal Predictors of the Sorcerer/Witch}

The original research reported the Sorcerer/Witch as significantly correlated with Political Integration beyond the local community and Social Stratification (multiple $\mathrm{R}^{2}=.70, \mathrm{p}<<.001$ ). These previous findings were partially confirmed here with the positive significant correlations with Political Integration and Intensive Agriculture, but not Social Stratification. Additional significant explanation of variance (multiple $\mathrm{R}^{2}=$ .62) was found with addition of variables assessing Judiciary (v89, positive correlation) and Community Integration (v73, negative correlation). These findings support a model of the Sorcerer/Witch as being produced in the activities of political integration and judicial processes, represented in the activities of the Priests and Healers who engage in ritual processes for designating who is a Sorcerer/Witch.

\section{Summary of Predictors of Religious Practitioners}

The analyses of the individual practitioners in relationship to social variables provide a more nuanced understanding of the social factors that produce the different forms of religious practitioners, and in particular, their transformation from one type to another. The complementary relationship of Shamans, Shaman/Healers, and Priests to foraging and intensive agriculture indicates that the latter was the first factor involved in the transformation of shamanism and the emergence of other religious practitioner types, notably the Priest, responsible for agricultural rituals for society. Subsequent increases in political integration and warfare further transformed the shamanic base, confirmed 
by their significant presence in regression analyses assessing prediction of Priests, Shaman/Healers, Healers, Mediums, and Sorcerer/Witches.

The analyses here present compelling evidence for the causal effects on religious forms (practitioner types) exerted by specific subsistence and political variables (particularly foraging versus intensive agriculture and political integration beyond the local community and warfare). These factors represent the principal forces causing cultural evolution of religious forms. Nonetheless, the analyses presented here may not have discovered all relevant causal factors. In all of these regression analyses (except for analyses of the Mediums and Shamanistic Healers), the Hausman test has a significant Wy (see footnote 5), indicating aberrant error terms, and suggesting the possibility of a better model. But in spite of screening a large number of related social, political, and warfare variable areas, no additional independently significant predictors were found in these analyses of the religious practitioners. In some cases, these incomplete models reflect the assessment of individual practitioners - just Shamans or just Shaman/Healer or just Healers - when these shamanistic healers obviously need to be represented in a more complex variable that encompasses all of them in a single measure that reflects their transformation from one form to another as a consequence of social change. This is confirmed by the lack of a significant error term for the Hausman test for the regression analysis for the computed Shamanistic Healers variable, suggesting a complete model has been identified when all of the shamanistic healers are included in a single regression variable. The error terms may also reflect the weakened regression analyses from the inclusion of the two societies in the sample (Mbuiti and Siriono) which were without formal religious practitioners but coded for communal activities. Their cluster analyses grouping justified their ad hoc categorization as a variant of the Healer variable (881d2), although the simplicity of their societies was not typical of the Healers overall. This lack of formal practitioners is not explained with the analyses performed hereto date although the extreme deculturation characteristic of these two societies suggests a possible cause (Winkelman, 1992).

\section{Common and Distinguishing Characteristics of Shamanistic Healers}

The differences of Shamans with respect to other practitioners of the Healer Complex and Mediums are examined with respect to the subsistence and political conditions of their respective societies to illustrate how distinctive features of the different practitioner types are related to these effects.

\section{Shamans (v879)}

The cross-cultural presence of Shamans in foraging societies illustrates that shamanism is an ecological adaptation that manifests features reflecting the ethos of a foraging society. This ethos emphasizes an ecological orientation, beginning with their training alone in nature, a solitary retreat in the wilderness, totally apart from society for weeks to months or longer. During their visionary initiation, Shamans are thought to be killed by animals, initiating a death-and-rebirth experience in which they assume animals in their personal power and identity. Animals epitomized and distinguished the specific nature of Shamans' powers. Shamans exercise animal powers through their alleged ability to send them to do tasks and even transform into an animal. The Shaman imitates and 
incorporates animals during the ritual performance, evoking powerful emotional reactions from the audience. Animal relations are further expressed in the Shaman's relationship to hunting, both appeasing the spirits of the animals killed and directing hunters' efforts through divinatory visions and organization of and participation in communal hunts. Shamans were renowned for their ability to call herds to waiting hunters.

A central feature of shamanism involves the altered state of consciousness (ASC) central to selection, training, and professional activities of divination and healing. The indication of selection of a Shaman typically begins with signs manifested in unusual visions, dreams, and illness, which are interpreted as the insistence of spirits that the person undertake arduous shamanic training that involved deliberate induction of ASC. Training involved a solitary vision quest in the wilderness imposing diverse austerities: extensive fasting; sleep, social, and sensory deprivation; endurance of pain and temperature extremes; and various emetic and other substances to facilitate induction of a visionary experience that gives powers to the Shaman (Winkelman, 1990, 1992, 2010a, b). The Shaman's development reflects the effects (and perhaps risks) of powerful ASC, for example as manifested in an experience interpreted as death-and-rebirth. Other Shamans' ASC experiences involved both a soul flight or magical flight, an experience of a conscious and personal soul aspect leaving the body and traveling to a spirit world; and the experience of personal transformation into an animal through which the Shaman was thought to be able to accomplish many activities (flying, divination, healing). The ASC is necessary for entry into the spirit world, another defining characteristic of Shamans. The biological effects of ASC and their elicitation of innate modular responses can explain the phenomenology of various shamanic ASC (Winkelman, 2010a).

Therapeutic activities of Shamans generally involved making a soul journey to recover the patient's lost soul or spirit that represented the patient's personal essence and powers, or through extraction of illness-causing objects or spirits sent by other Shamans. Shamans used herbal medicines and other natural substances, physical techniques such as massages and prodding, heating the patient's body and covering it, and stroking the body with feathers. Shamans also provided a range of biological treatments derived from plants and natural substances. Shamans also employed healing methods eliciting innate healing responses involving hypnotic susceptibility, dissociation, and placebo effects, as well as the effects of ritual elements (social closeness, singing, dancing) on the endogenous opioid system and the modulatory serotonergic and dopaminergic neurotransmitter systems (Winkelman, 2017a).

\section{Shaman/Healer (v880)}

Shaman/Healers were overall very similar to Shamans, notably amalgamating with them before the inclusion of Healers in some cluster analyses. Agricultural Shamans is an appropriate synonym for these practitioners reflecting their significant correlation with Intensive Agriculture and its role as a key significant predictor (negative) with respect to Shamans. Agricultural Shamans share the core features of Foraging Shamans in their selection and training involving ASC and professional activities providing healing, divination, and protection against spirits but begin to differ from them in ways 
that reflect the effects of their more complex agricultural societies with a Priest present, and who was considered of a higher status than the Shaman/Healer.

Although Shaman/Healers were also thought to be selected by spirits who revealed their request in visions, dreams, and illness, the training was provided by a collective organization of Shaman/Healers. This organization confers ceremonial recognition upon completion of professional training and organizes group activities. Shaman/ Healers also had role specialization among practitioners, each specializing in one area such as diagnosis, healing specific kinds of illness, or agricultural rites; this would reduce intra-group competition among the practitioners.

The source of Shaman/Healers' powers was derived from both spirits and impersonal sources, such as a transferable personal power like mana or derived from the inherent power of ritual techniques or spells learned from their teachers. The Shaman/ Healers used ritual techniques for alteration of consciousness, engaging in practices of drumming, singing, chanting, austerities, and fasting. But while they were thought to interact with the spirit world, they did not all report the shamanic "soul journey."

The subsistence differences between societies with Shamans (foraging) and Shaman/ Healer (intensive agriculture) (with the latter notably providing for sedentary lifestyle and larger more complex populations) explain the major differences between these two practitioner types. This primarily involves the Shaman/Healers' involvement in agriculture rituals and participation in organized groups, a possibility enabled by the closeness of a larger population and hence many Agricultural Shamans together. This agglomeration of Shamans is not possible under normal foraging conditions. This increased population enhanced contact among practitioners and enabled Shaman/ Healers to engage in group functions such as training and role specializations. These subsistence differences - intensive agriculture - also predict the presence of the Priest, who has a higher social status than the Shaman/Healer, a decline from the Shamans' pre-eminent status in foraging societies. The size of their respective populations appears to account for another feature that distinguishes them. While Shamans carry out community-wide rituals with the participation of all of the local group (band), the Shaman/Healer typically provides healing rituals in the client's home.

\section{Healers (v881)}

Healers' professional responsibilities also involve diagnosis and healing of disease and other forms of divination. A steady stream of income came from their services as officiants required for life cycle rituals such as naming ceremonies, marriage, and funerals. Healers also collaborate with Priests in agricultural ceremonies and other cyclical rituals of propitiation of common gods.

Healers differ from other Shamanistic Healers in being self-selected in paying other Healers for costly training, rather than being thought to be selected by the spirits. This training involved learning spells, formulas, and ritual techniques for diagnosis and healing. Healers generally had lucrative practices that enabled them to be full-time specialists and recoup their training fees. The power of Healers was mediated through their professional organizations, which wielded considerable power in society.

Healers were generally exclusively male, and had high social and economic status, as well as political, legislative, and judicial powers. These features reflect the significant societal association of Healers with Political Integration beyond the local 
community, Community Integration, Warfare, and Jurisdictional Hierarchy. The negative weighting on this latter variable may reflect Healers' function in judicial proceedings to evaluate accusations of sorcery and their power to determine who is a Sorcerer/ Witch and authorize their punishment.

Healers generally lacked any major alterations of consciousness and the entry into the spirit world typical of other shamanistic healers. Healer's relations with the spirit world were with respect to the society's superior spirits (often "high gods"). The presence of Healers in a society is often complemented with the position of the Medium, who more directly engages with the ASC characteristic of shamanistic healers. ASC may nonetheless affect patients through hypnotic incantations and susceptibility to placebo effects. Lacking the divinatory visions characteristic of Shamans, Healers used material systems such as divining baskets with ritually significant objects, which they manipulated and interpreted in light of the patient's situation in order to make diagnoses. Exorcism was the central healing activity, addressing patients' concerns with the ill effects of possessing spirits. Their ritual healing activities employed spells, charms, and imitative techniques to control and exorcise spirits, who also might be appeased to desist with sacrifices.

Healers' association with higher levels of political integration (beyond local community), a significant variable implicated in the decline of Shamans and Shaman/ Healers (who were found in societies without political integration beyond the local community), is reflected in Healers' roles in exercising political, legislative, and judicial powers.

The differences of the Healers in comparison to the Shamans raise the question of whether they can be considered a form of shamanism. The amalgamation of Healers as a group prior to merging with Shaman/Healers and Shamans indicates they are not Shamans. The Healers lack features which are the core features of Shamans: powerful ASC such as soul flight, death-and-rebirth, and animal transformation; a source of power in animals; healing ideologies based on concepts of soul loss and recovery; collective community-wide nighttime healing rituals; and the practices of sorcery. Given these extensive differences, conceptual clarity requires differentiating Healers but, nonetheless, recognizing their commonality as shamanistic healers, a human universal involving institutions to ritually induce ASC to interact with the spirit world for purposes of healing and divination. The degree of relationality of Healers with other shamanistic healers can be further addressed empirically using the heretofore unanalyzed new variable codes (see Winkelman and White 1987; also see footnote 4).

\section{Mediums (v882)}

As is the case with the practitioners of the Healer Complex, the Mediums have principal role functions of diagnosis, divination, and healing; they also participate in agricultural rituals and propitiation. Mediums are the only practitioner type that is predominantly occupied by women, and when men are Mediums, they too are generally low status. While Mediums are respected within their families, professions, and local community, they are generally of an overall low social status in society compared to other religious practitioner types.

As the case with Shamans, Mediums are thought to be selected by spirits, but differ in their typical selection in a spontaneously and dramatic seizure interpreted as 
manifesting symptoms of an illness considered to be caused by possessing spirits. Their initial possession episodes generally occur in late adolescence or early adulthood, and the treatment of this condition by a group of Mediums initiates their learning to control the spirits. This development involves giving a voice to the spirits through their own vocalizations, allowing the spirits to specify their demands to the assembled people.

The possession of the neophyte, as well as developed Medium, manifests abnormal brain discharges in features such as convulsions, agitated motor behavior, tremors, seizures, and dissociation, as well as amnesia for the experience, features not normally found with other shamanistic healers (Winkelman, 1986b, 2010a). Possession features resemble recognized clinical profiles often associated with enhanced religiosity (temporal lobe and the ictal personality syndrome) (see Winkelman, 2010a; Schachter, 2006). Mediums' possession states manifest features of dissociation, a survival adaptation facilitating continued relations with people who cause trauma (Sar \& Ozturk, 2007; Sar, 2017). This psychodynamic of possession reflects the oppressive social conditions experienced by women who typically occupy these roles (Bourguignon \& Evascu, 1977), a factor confirmed here by the finding of Mediums' significant prediction with a form of warfare specifically involving taking of captives.

Mediums engage in rituals to worship and propitiate their possessing spirits and make sacrifices to them. The diagnoses generally indicate illness from possession requiring treatment with exorcism, or else rites to provide protection from malevolent spirits and witches. Healing occurs through moderating the effects of the possessing spirits, appeasing them with sacrifices in order to end their affliction of the patient. The possessing spirits also provide a therapeutic mechanism in the dramatic changes in emotions expressed by the patient/Medium. Mediums use the expression of the powerful spirits to relieve some of the suffering of their subordinated role by expressing emotions that are normally prohibited for women. The Mediums are able to exert informal social influence through expressing utterances that are attributed to a powerful spirit. The Mediums, by presenting their own demands in the voice of a socially respected spirit entity (via the practices of possession spirit communication), are able to resist and counter the dominant power relations exercised by men, who may be cowered into accepting the demands of the possessing spirits.

Although they are frequently called shamans, Mediums are not Shamans. The cluster analyses have them as a separate group before amalgamating with the Healer Complex. While Mediums manifest a central concern with alterations of consciousness, as do Shamans, they differ from them with possession rather than the soul journey characteristic of Shamans. Furthermore, with the Mediums, the spirit communication roles are transformed with the Medium unconsciously channeling spirit communication to the community: Shamans control spirits, Mediums are controlled by spirits. Mediums lack animal relations, reflective of their presence in agricultural rather than foraging societies. Most of Mediums' features, apart from their general engagement in ASC, spirit relation, diagnosis, and healing, are distinct from Shamans'.

\section{Discussion: the Social and Biogenetic Bases of Religious Life}

The empirical typology of religious practitioners discovered in this cross-cultural research establishes the etic status of Shamans, Priests, and other types of religious 
practitioners based on their actual characteristics rather than arbitrary definitions or imposed etics. This empirical similarity reveals a universal paradigm for interpreting religious practice and ritualists that is more relevant than arbitrary definitions. The appropriate use of such terms as Priest, Shaman, Mediums, and Sorcerer/Witch can validly represent the characteristics of religious practitioners when based on these ethnological models which reflect the empirical features discovered in cross-cultural research.

The empirically derived features of the Shaman presented here correspond to many of the features of the impressionistically based characterizations of Shamans found in both the academic and popular literature. But many intuitive characterizations used in the anthropological literature also differ considerably from this empirical profile. Notably, even many scholars that wish to use (or deny) the term shaman as a crossculturally valid concept do not rely on systematic ethnological research for identifying the features they espouse (or reject). Instead, they insert various traditions, biases, and assumptions to argue some particular definition of shamanism, or to even assert that no cross-cultural patterns exist. Even researchers that have called for the use of etic models, or claim that they justify a particular cross-cultural concept of shamanism, have made their judgements on whether something constitutes shamanism on the basis of arbitrary definitions rather than on ethnological models, even when they cite and applaud such scientific activities. Consequently, the label of shaman is applied to many different types of religious practitioners with distinctly different characteristics, such as Mediums identified here.

Characteristics typical of Shamans may be found in other religious practitioners, including beliefs about soul flight or animal identities without the practitioner being a Shaman. For instance, Craffert's (2008) book The life of a Galilean shaman: Jesus of Nazareth proposes that shamanism offers a framework for interpreting the life of Jesus of Nazareth. Jesus may be seen as having shamanic features: prolonged periods of fasting and solitude in the wilderness; visionary experiences, perhaps even something like the soul flight; an association with animals ("Lamb of God"); a death-and-rebirth experience; and functioning as a healer. But this does not make Jesus a Shaman as his alleged life features lack many of the features of the Shamans found cross-culturally, notably overnight rituals of dancing and singing and drumming; dismemberment; control of animal spirits; transformation into an animal; and healing through soul recovery and sorcery extraction. Instead, Davies (2015) demonstrates how Jesus manifests the features of a Medium in being controlled by a higher spiritual power ("possession by the Holy Spirit") and healing through exorcisms of demons.

The empirical evidence justifying a more restricted use of the word shaman has not convinced academics or the popular culture to abandon this loose tradition of including many different types of religious practitioners under the rubric of shamanism. This over-extension has many roots, including a failure to understand the different characteristics of the various types of shamanistic healers. Nonetheless, the Shamans, who were found in foraging societies, have features that distinguished them from other religious healers (Mediums, Healers, and Shaman/Healers); these facts reinforce the need to maintain conceptual clarity when making cross-cultural comparisons in scholarly communication, and using distinctions based on empirical differences rather than arbitrary definitions. This means clear distinctions and labels that reflect them, 
especially the distinctive features of the Shamans of foraging societies and their differences with respect to other shamanistic healers, the Mediums in particular.

The term "Forager Shaman" can be used to distinguish this primordial huntergatherer phenomenon, in accommodation to the appropriated and generalized use of the term and concept of shaman. This distinction as a Forager Shaman is empirically justified on the basis of the positive prediction of Shamans by the combined measure of foraging (Overall Foraging, i.e., gathering, hunting, and fishing) and its negative correlation with Intensive Agriculture. In direct contrast, Shaman/Healers are strongly predicted by Intensive Agriculture, justifying the synonym Agricultural Shamans. The encompassing term Shamanistic Healers can be used to refer to these and other practitioners who alter consciousness to achieve spirit communication, healing, and divination. Other types of Shamans may be justified, for instance reflecting the dynamics of transegalitarian societies and their new ritual dynamics (see Hayden, 2003 and below).

So at what point do we say the practitioner is no longer a Shaman but is a Healer or a Priest or a Sorcerer/Witch? This can be determined empirically and some of the relevant features are presented in Tables 1, 2, and 3. Further features that differentiate Foraging Shamans and Agricultural Shamans from each other and other practitioners can be derived from the updated and extended dataset (see footnote 4). However, such determinations must be conceptual as well as empirical, and the cross-cultural research reported here indicates some basic core features that should guide inclusion or exclusion as Shamans:

Selection Processes: Spontaneous and deliberate alterations of consciousness, open access with individualistic training

Alterations of consciousness: out of body experience (soul flight), death and rebirth experiences, transformation into an animal

ASC Induction: fasting, austerities, singing, drumming, dancing, psychoactive substances

Animal spirit relations: animal powers, animal identity, control of animals, hunting magic, animal transformation

Primary functions: healing, divination, and malevolent acts

Social Characteristics: High status charismatic leader

Rituals: primary ritual technique is the overnight community ceremony

Healing dynamics: overnight ritual ASC, soul loss, intrusive sorcery (object extraction) and spirit aggression, physical manipulations (i.e., massage) and plant medicines.

\section{The Social Determinants of Religious Life}

These new analyses confirm the importance of social factors in the different forms of religious life. Of central importance is the role of political integration in the transformation of religious practitioners, not just in the decline of Shamans and Shaman/Healers, but also in the emergence of Priests, Healers, Mediums, and the Sorcerer/Witch. This indicates that higher degrees of political integration co-occur with the emergence of these new religious types; the new results suggest these involved processes of warfare and increased political 
integration into larger communities. But apart from Political Integration, the most significant predictors of the various religious practitioners are subsistence activities, specifically implicating ecological relations involving an Overall Foraging lifestyle versus Intensive Agriculture. The Shaman's cosmology and ecological relations are directly linked to the foraging lifestyle involving relationships with the natural world and animals in particular. In contrast, Shaman/Healers are significantly predicted by Intensive Agriculture, as is the presence of the Priest, the Shamans' polar figure. These significant relations with respect to Intensive Agriculture show how changes in technological (subsistence) and ecological relations are fundamental to the cultural evolution of religion. The major ritual responsibilities of the Priests make it clear that a fundamental concern in the evolution of religion involves agricultural traditions.

Alternative hypotheses for the emergence of Priests and Healers may be found in Hayden's (2018) argument regarding the role of "secret societies" (sodalities) in driving the emergence of chiefdoms and early states. These societies were not so much secret as sodalities, private voluntary, and restrictive organizations that provided mechanisms for increasing wealth and power of its members through the appropriation of surplus production from others in society in the form of tribute. This accumulation of economic and political power contributed to the evolution of social complexity and social stratification through their success in transcending kinship by forming groups based on fictive supra-kinship organizations that provided extensive networks of contacts that transcended even ethnic boundaries and the functions of clans with a rudimentary aristocracy that accumulated extracted surpluses from society. Hayden proposes that this control of resources by the sodalities contributed to formation of chiefdom-level political organizations through the use of ritual and religion as tools for political control and territorial expansion. Such factors may also produce Healers.

Further research can identify conditions leading to the need for agriculture and political integration and producing the emergence of Priests, Healers, Mediums, and Sorcerer/Witches. The updated dataset available (see footnote 4) extends the original variables used for the analyses presented here and provides opportunities for new analyses. There is a need to further clarify the distinctions among shamanistic healers and examine whether there is a replacement of Shamans and Shaman/Healers by Healers or whether they gradually transform into Healers. Future analyses should consider testing hypotheses regarding the effects of other political variables on religious practitioners, such as resource accumulation and surpluses examined by Hayden (2003), as well as the roles of kinship systems, population dynamics, and political processes that Winkelman $(1998,2014)$ has identified in cross-cultural analyses of predictors of human sacrifice.

\section{Biogenetic and Biosocial Bases of Religion}

How can religious practices, often alleged to be based on ephemeral beliefs, exhibit a common structure of features and ritual in practitioners found cross-culturally? The selection-function relationships presented above reveal fundamental social forms of religion derived from biogenetic dynamics that produce these cross-cultural regularities. These biogenetic bases are manifested in variable ways as a function of societal conditions, especially subsistence and political organization, illustrating how social influences on these biological capacities produce variable types of religious 
practitioners under specific conditions (i.e., Shamans versus Mediums). Biosocial dynamics are also revealed in the emergence of Priests in societies with intensive agriculture and the emergence of the Sorcerer/Witches in societies with high levels of political integration.

The original biogenetic basis of religion involves the use of ritual alterations of consciousness for purposes of healing, a universal of religion found in virtually all societies. This primordial function of religion derived from biological processes inducing alterations of consciousness that facilitate endogenous healing responses (i.e., placebo and hypnotic susceptibility). This biogenetic feature is manifested in the Shamanistic Healers (all Shamans, Shaman/Healers, Mediums, and some Healers). The relationships of the different subsistence and social conditions to the various types of shamanistic healers reveal the biosocial dynamics, that is, how social conditions affect these underlying biogenetic dispositions. Shamanism provides a biogenetic structural framework for the origins of religion and cross-cultural distribution of ritualized healing practices that is manifested in not only Paleolithic evidence (Winkelman, 2002a, b), but much deeper in the dynamics of hominid ritual and its expansion across hominin evolution (Winkelman, 2009, 2010b, 2019b).

A second biogenetic function of religion derives from kin-based preferences manifested in descent-related inheritance of political power that provides a hierarchical structure for social control, organization of agriculture cycles, and propitiation of common gods. Ancestor worship, as well as the highest level of the hierarchy of Priests, typically manifests this role selection through social succession (through male kin, typically father to son). This biogenetic basis for religion in kinship principles emerges as formalized Priests under conditions of intensive agriculture and the need for hierarchical political integration. These factors lead to elevation of these primordial biologically based kinship biases into society-wide preferences through practitioners that control economic, legislative, judicial, and other forms of political power. This power is reinforced through their public performance of seasonal rituals related to agricultural well-being that also engage propitiation of collective high gods.

A third biosocial function of religion exploits a biogenetic dynamic of out-group discrimination, an in-group versus out-group moral dualism that justifies moral condemnation and violent elimination of stigmatized members of marginalized and subordinated out-groups. This involves designating people as malevolent religious practitioners through social labeling and persecution of them through allegations of immoral and anti-social supernatural activities. The biosocial dynamics of these tendencies is illustrated by the presence of Sorcerer/Witches practitioners in societies with political integration beyond the local community; and the presence of these alleged practitioners in marginalized lower-class groups, illustrating that this dynamic is elicited by specific social conditions.

The following sections elaborate the manifestation of these biogenetic bases and their biosocial functions.

\section{Shamanistic Healers: Alteration of Consciousness and Healing}

A cultural universal is represented by the Shamanistic Healers (Shamans, Shaman/ Healers, Mediums, and most Healers), religious practitioners who engage ritual ASC as a basis for professional activities that principally involve healing and divination. The 
presence of a common pattern of behavior worldwide manifested in the Shamans of foraging societies attests to its derivation from innate features of human nature as developed under the influence of a foraging lifestyle. This original manifestation eventually disappears with the loss of foraging and the influences of agriculture, warfare, and political integration, but its core elements remain in society, albeit in modified form.

What are the underlying biological dispositions producing this worldwide manifestation of a common pattern of complex religious behavior among foragers and some agriculturalists and which continues in other Shamanistic Healers?

Winkelman (2010a) proposed the bases for shamanism involve the incorporation and extensions of adaptive complexes acquired across hominin evolution because of benefits from ritual. The shamanic paradigm (Winkelman, 2010a) provides a biogenetic framework explaining these shamanic origins of religion that expanded the dynamics of hominid ritual across hominin evolution through the ritual enhancement of social integration and endogenous healing responses (Winkelman, 2002a, b, 2009, 2010a, b). The role of Shamans as charismatic leaders and their unparalleled ritual displays have deep roots in hominid conspicuous displays. This shamanic origin is revealed in its homologies with chimpanzee maximal displays, particularly collective nighttime reunification displays of vigorous group chorusing, hand and foot drumming, and bipedal charges (Winkelman 2009, 2010a). Hominin evolution and shamanism expanded the social integration dynamics produced by hominid collective displays through the mimetic capacity, manifested in dance, imitation, singing, and drumming (Winkelman 2009, 2010a, 2015, 2019a). Dunbar (2017, p. 353) proposed that shamanism evolved as adaptations providing mechanisms to elicit endorphin responses in order to enhance group social bonding. Synchronized social activities such as singing and dancing provoke the release of endorphins (Launay et al. 2016). These collective activities expanded on hominid displays with the opioid elicitation effects of synchronized singing and dancing. These activities helped to overcome limitations on social grooming created by increased group size, compromising its role as a mechanism to elicit endorphins (Dunbar 2014).

Such ritual activities also induced alterations of consciousness (Winkelman, 2011a, b, 2013a, b) which elicit endogenous healing responses (Winkelman 2008, McClenon 2002). Shamanistic Healers are universal because the ASC that are the basis of their selection, training, and treatments reflect a common biological response to diverse circumstances (Winkelman 2010a, 2011a, b, 2017a, b). Common biological effects of diverse ASC involve coherent brain wave discharges that ascend from lower levels of the brain and entrain the frontal cortex with synchronized slow-frequency brain waves, integrating normally unconscious processes into the frontal cortex (Mandell 1980; Winkelman, 2010a, 2011a, b). These dynamics stimulate the release and integration of innate processing modules (innate intelligences; Winkelman 2017b, 2018), producing a cross-modal synesthesia that is experienced as visions. These visions are manifestations of integration of information across innate intelligences that produce our innate animistic psychology (Winkelman 2013b) and various primitive forms of symbolic thought (i.e., presentational symbolism, totemism) (Winkelman 2002a, 2010a, 2018, 2019b). Shamanic ritual practices produce this overall brain dynamic through extensive dancing, fasting, and auditory stimuli from drumming and chanting that produce increases in endogenous opioids, serotonin, and dopamine (Winkelman 
2017a). Shamanic ritual and ASC evoke numerous healing mechanisms from counteracting anxiety to social support, with a range of salubrious psychophysiological effects (see Winkelman 2008, Chapters 9 and 10; 2010a Chapter 5), including stimulation of endogenous opioid responses; producing a shift to parasympathetic dominance, evoking the relaxation response and counteracting stress hormones; inducing hypnotic susceptibility and eliciting placebo responses; enhancing access to the unconscious; and engaging diverse psychophysiological and psychosocial mechanisms that enhance psychoneuroimmunological responses.

Previc (2009) proposes that the human drive to seek ASC directly engages the dopamine system, which is stimulated by diverse agents and ritual conditions (also see Winkelman 2010a, 2017a). Exogenous sources of neurotransmitters also produced ASC and contributed to the evolved psychology of shamanism (Winkelman 2021). Common to ASC is a disinhibition of dopaminergic extrapersonal brain systems, enhancing dopaminergic effects that stimulate cognitive processes key to the modern human psyche. Dopamine is involved in humans' unique cognitive abilities involving goal-directedness, learning stimulus associations and reward prediction, cognitive shifting, abstract representation, and distal temporal processing, as well as generativity and creativity (Previc 2009). "[D]opaminergic activation results in the 'triumph' of extrapersonal brain activity over the body systems that anchor our self-concept and our body orientation as well as a triumph over the more 'rational' executive intelligence" (Previc 2009). The dopaminergic-induced abstract thought is exemplified in shamanic out-of-body experiences and conceptualizations of spirit worlds, agent concepts that expand human capacity to explore our internal cognitive structures through symbols embodied in spirit concepts. Previc (2009) notes that shamans have features characteristic of highly dopaminergic minds - charismatic, intelligent, and confident, seeking connections to unseen forces, as well as aggressive drives to achieve distant goals, magical ideation, and delusions of grandiosity, invincibleness, and the ability to control others and distant events (paragraph summarized from Winkelman 2019c).

\section{Priests and Totemic Cults: Roles of Ancestors in Cultural and Religious Life}

The conventional understandings of what constitutes religion are represented by those activities embodied in the practices of Priests. The Priest is the religious practitioner that is the most important contrast with the primordial role of the Shaman, engaging in calendrical (seasonal) rituals for agricultural fertility and propitiation of collective gods. The etic profile of a Priest provided in Tables 1, 2, and 3 illustrates an ethnological analogy for these practitioners. What is the origin of this central and currently dominant stratum of religious practice? Durkheim (1915) proposed the origins of religion in totemic practices that originate in clan structures, using as a model the collective ritual practices of a technologically simple society (the Australian Arunta described by Spencer and Gillen [1899]). The expressed/manifest purpose of the ritual worship was a feast to promote and assure the continued growth and well-being of the totem animal which clan members were normally prohibited to consume. The totem animal species worshiped by the clan is considered to be a representation of that social group and their sacred deity, simultaneously a symbol of social identity and their god. The totemic ritual brings together all members of the clan, physically uniting society together in the annual ritual. This basic social function led Durkheim to conclude 
that totemic ritual practices were the most basic and original form of religion and that this primitive form of religion involves the worship of society.

Steadman, Palmer, and Tilley (1996) similarly argue for an origin of religion in ancestor worship, ritual practices that address one's deceased ancestors as the most important spiritual beings. Ancestor worship exapts adaptations for kinship preferences and reflects a suite of adaptative capacitates related to the emulation of elders (Palmer, Ellsworth \& Steadman 2009). Adherence to ancestors' instructions and expectations is central to the formation of culture, an ancient and core part of humans' cultural adaptations to the ecological and social niche. The ancient roots of the practices of ancestor worship must have derived from the benefits of emulating older kin, especially those who are well-skilled socially (Palmer, Ellsworth \& Steadman 2009).

But Durkheim's theory that totemism was the most fundamental and primitive of all cults, and thereby the origins of religion, neglected to consider another significant aspect of Arunta religion, what Spencer and Gillen (1899) referred to as "medicine men." Durkheim ignored this practice because he discredited them as "magic" which he wished to distinguish from religion. These practices involved shamanism (Elkin 1978), which the research presented here and other cross-cultural research (Peoples, Duda and Marlowe 2016) show to be a prior stratum more ancient than ancestor cults. The sequential emergence of forms of religious practice and practitioners is shown by Peoples et al.'s (2016) phylogenetic reconstruction of the evolution of religious practices, which used a cross-cultural database of hunter-gatherer societies. Their evidence shows the sequential emergence of the following: first, animism; secondly, both a belief in an afterlife and shamanism; then ancestor worship; and later high gods. Peoples et al. (2016) also found that while ancestor worship is attested to in some hunter-gatherer societies, this concept of concerned ancestor spirits, which may be raised to formalized rituals of ancestor worship, is not widespread among huntergatherers, indicating it evolved more recently. And since ancestor worship practices may be lost, it is a labile trait which depends on specific circumstances for supporting its institutionalization.

This priority of animism and shamanism cross-culturally and across time shows they represent a more ancient strata of religious belief than ancestor cults. This later phase of the social evolution of religion eventually superseded-but not completely replaced - the original religious forms provided by shamanism. Nonetheless, ancestors were also key figures in shamanism, often identified as the spirits making the call for the neophyte to undergo training and providing the initiate with their animal powers.

These ancestor-oriented religious practices emerged long before the development of intensive agriculture, manifested in complex hunter-gatherer groups who performed public rituals for the enhancement of the prestige of their reproductive groups with conspicuous public feasting and monumental architecture made possible by foraging surpluses and extended lineages (see Hayden 2003). This leadership by well-qualified elders extends the general organizational power of lineages. Given the key role of belief in and adherence to ancestors' demands in the formation of culture, such implicit practices must be very ancient and represent the deep origins of Priests. The head Priests are typically selected on the basis of descent from an immediate ancestor who was a Priest, and by extension acquiring leadership over their lineage and the broader society. 
The continuities of ancestor worship and Priests are shown in the case of the Roman ancestor cults included in the analyses here as a test case, which was clustered with the Priests. Thus, these ancestor worship practices that were originally familial activities appeared to have evolved into societal-wide practices that led to the emergence of Priests as supreme political and religious leaders. These potentials of ancestor cults may have been extended and formalized in the positions of Priests as adaptations to the demands produced by agricultural societies, particularly when there was a need for political integration beyond the local community.

\section{Sorcerer/Witches as Social Persecution and Political Integration}

The Sorcerer/Witches are attributed immoral activities, and generally conceptualized as such an antithesis to religion that they are not even considered in many characterizations of the scope of religious behavior. Nonetheless, the negative and devalued behaviors - or beliefs_represent aspects of the supernatural that are central concerns of what is conceptualized as the domain of religion in many societies. Consequently, supernatural evil must be part of any comprehensive consideration of humans' supernatural beliefs, including what is considered to be a religious practitioner such as a witch, whether or not they actually exist as conceived.

The core concern of religion with supernatural evil is illustrated by these Sorcerer/ Witches' direct relations to the functions of Priests and Healers, who are the central societal agents determining who is guilty of this antithesis of the moral order. The significance of these attributive processes is shown in many histories that document how the designation of witches provided significant economic rewards for the accusers and those who judicially process the accused and obtain control of their properties upon conviction.

The findings of this study establish the cross-cultural similarity in the empirical features of the Sorcerer/Witch practitioner. This indicates that the bases and formative processes are not arbitrarily cultural, but a consequence of social factors forming the phenomena of the Sorcerer/Witch. These are exhibited in the shared social characteristics of this religious practitioner type, a status that is generally attributed by others (Priests and Healers) rather than self-proclaimed or even admitted to by the accused person unless they are forced to do so. The Sorcerer/Witch is at the margins of society, generally of the lowest social status, where they are further oppressed through processes of ascription of immorality and often publicly killed.

These beliefs attributed to the Sorcerer/Witches have a basis in more than just the fanatical accusations of the Priests and Healers. While the Sorcerer/Witch is distinct from Shamans, there are nonetheless features that link them. Shamans and Sorcerer/ Witches share the following (alleged) activities: nighttime ritual activities; causing illness and death; association with animals, including transformation into animals; consuming the body or soul of the victim; and the ability to fly (Winkelman 2010a). Shamans and Sorcerer/Witches have an exclusion relationship in that if one is present in a society, the other is absent. This would be the case if shamanistic practices were the origins of witchcraft beliefs. This suggests that societies with shamanic practices, when under processes of political integration into larger societies, find their shamanistic 
healers and their characteristics distorted to justify their persecution by Priests and Healers.

The contradiction of the characterizations of witches as immoral agents versus their engagement with healing rituals such as that found in modern witches and Wicca is explained by the analyses presented here. These differences involve perspectives from different levels of political integration (hierarchical versus local): the moral order imposed from a higher level of political integration (i.e., church) on local-level activities involves attributing characteristics to them to justify their persecution. The Catholic Church began in the fourteenth century to prosecute folk ritual practices as heretical witchcraft, accusing village healers, often women, of killing and eating children and diverse sexual perversions, participating in clandestine sects that worshiped the devil, and practicing perverse rituals to cause illness and death to people and destroy animals and crops (Ostorero 2019). But the accused, known locally as healers, blessers, soothsayers, exorcists, magicians, charmers, and fortune tellers, used divination to identify witches and other causes of illness and find thieves and treasures and locate lost objects. They offered healing services for people and animals involving incantations, invocation of spirits, counter spells against witches, charms and amulets, rituals involving imitative and image magic, and applications of herbal medicines (Bever 2008).

This dimension of religion involving the oppressive religious persecution of subordinated people and practices helps explain a persistent issue in the comparative study of religion: why is it that religion-and religious authorities and religious studies experts - strive to exclude witches from discourse about the realm of the supernatural? The answer from the present research is that this reflects the same motivation found in efforts by Priests to morally define who is a Sorcerer/Witch, justifying political persecution of competing social and religious forces at local levels in hierarchical societies. This oppression of competing religious ideologies occurs at the community level where shamanistic healers are violently eliminated in the process of political integration by a hierarchical religious ideology.

\section{Application of Ethnological Models to Archaeological Interpretation}

These ethnological, biogenetic, and biosocial models reveal robust cross-cultural patterns that can be used in the interpretation of archaeological and historical data. A primary source of data about prehistoric Shamans comes from burials. Ensor, Irish, and Keegan (2017) show that cultural beliefs and practices are reflected in interment practices, and that cross-cultural data on postmortem locations of males and females and their correspondence with marriage and descent group practices provide context for interpretation of bioarchaeological data. They point out that ethnologically derived models of kinship can significantly enhance interpretation of biodistances among interred individuals since where and with whom people are buried differs as a function of kinship practices. Just as cross-cultural models of kinship provide frameworks for interpretation of bioarchaeological data and making reliable inferences about aspects of social life in the past (i.e., kinship systems and marriage strategies [Ensor, Irish, and Keegan 2017]), so too can ethnological models of religion provide frameworks for inferring the nature of ritual practices revealed by burial goods. This section examines 
claims about shamans in four contexts-Ancient Eurasia, China, Maya, and the Paquimé to illustrate the usefulness of the model in evaluating the nature and appropriate labeling of ritualists.

\section{The Quest for Shaman Burials of Ancient Eurasia}

Aldhouse-Green and Aldhouse-Green (2005) begin their quest for archaeological evidence of shamans noting the "basic questions to consider: namely, what is shamanism and how can we recognize it archaeologically" (p. 10). But they later vitiate rigorous consideration by quoting "Shamans are at once doctors, priests, social workers and mystics" (p. 161). Without reference to any systematic study, they state that a shaman must have:

Trances involving soul journeys to the spirit world expressed as flying or swimming;

Symbolic death and dismemberment;

Activities of healing and hunting;

A three-tiered cosmos;

Use of the drum and other percussive instruments such as rattles, gongs, or bells; Relations with animals, especially birds suggestive of shamanic flight; and

Trans-species identity expressed in therianthropes.

Most such features are justified by the ethnological model present here, but they also allege other features of shamans such as divining rods, wands, and staffs of authority, diseased and disfigured bodies, gender fluidity, and caves. Features identifying ancient shamans cannot be limited to the characteristics of Shamans verified through the present ethnological model, but additional criteria should be consistent with the biogenetic model presented here and systematic findings derived from excavations and confirmed with local collaborative ethnography. Unfortunately, many sites Aldhouse-Green and Aldhouse-Green analyze have few of these characteristics and there is no presentation of systematic analyses of shaman burials to identify their features.

As Aldhouse-Green and Aldhouse-Green note, whether the "Red Lady" from Goat's Hole, Paviland, Wales, was a shaman "is almost impossible even to approach" (p. 35), but they nonetheless conclude the site was "appropriate for the grave of a shaman" (p. 63). The "shaman burial" in the Czech Republic involves a diseased body (periostitis) interred far from a settlement with a figurine, shells, antler, a rhinoceros skull, and large herbivore tusks, bones, and teeth. The presence of a modified reindeer antler interpreted as a drumstick suggests shamanic features, but there are no analyses presented to indicate the skulls or disks were used for percussion. The painful deformities suggest a "life of chronic pain, and perhaps related psychological trauma, might have given him social recognition as a shaman" (p. 35). Shamans are recognized for their role based on successful performances, not because they have deformities, pain, and trauma, although such factors may predispose shamanic development. Aldhouse-Green and AldhouseGreen assert that the bones are "typical accoutrements of a shaman's costume ... [and] suggests that the Brno II burial was very probably that of a shaman” (p. 63). But they provide no evidence for the association of bones and shamans' costumes. There is little evidence of the criteria they propose for shamans; animal bones were not established as 
distinguishing shaman from non-shaman burials, and may reflect foods rather than power animals.

Aldhouse-Green and Aldhouse-Green analysis of artifacts of the Iron Age illustrates problems that result from lack of a clear empirical model of Shamans and their differences from other ritualists. Numerous bog burials, particularly of men who were violently killed, have little credence of being shamans, in spite of cases with significant quantities in their gut of ergot, a hallucinogenic which is potentially fatal. AldhouseGreen and Aldhouse-Green propose these men were killed because ergot poisoning produces uncontrolled and wild behavior and strange contorted movements, but there is no evidence presented that these victims were shamans. Their execution would be more characteristic of a Sorcerer/Witch.

Another Iron Age example is from a man's grave in Essex that included "a set of Roman-style surgeons' tools, eight rods (four of bronze, four of iron) and a strainingbowl . . . the medical kit and the set of rods is highly suggestive [of] . . . a shamanhealer (p. 123) ... . we may be seeing a shaman's grave" (Plate 23). While the bowl contained a psychoactive plant (artemisia), the surgeon's tools ought to be seen as diagnostic feature of someone operating in physical medicine, not shamanism. The rods allegedly used for divination are not a form of divination associated with a Shaman, but typical of material systems used in Healers' divination. Aldhouse-Green and AldhouseGreen suggest images of shamans in Iron Age coins and artwork depicting naked horsewomen galloping "with their arms flung wide, as though in a state ecstatic frenzy" (p. 128) and winged human and animal figures with bug-eyed faces resembling the stress of shamanic trance (pp. 210-211). The evidence is not convincing, especially in light of their presence in politically complex societies different from those characteristic of Shamans and Shaman/Healers who are found where political integration is limited to local levels. Later assertions indicate that the ritualists they identify are not Shamans, but rather Healers or Mediums considered by society to be Sorcerer/Witches: "in early medieval Britain and Europe, shamans were also marginalized members of society, a shadowy underclass condemned by the Christian Church but still regarded as a force sufficiently dangerous and destabilizing to cause King Alfred to make it a capital offence for women to practice magic and cast spells" (p. 148).

Another example presented by Aldhouse-Green and Aldhouse-Green of an alleged shaman is Veleda, a German seer, related in Roman accounts. She was a secluded prophetess who made divinations that influenced political decisions following her prediction of a successful rebellion against the Roman army in Bavaria in 69 AD. Veleda was unmarried and highly secluded in a tower, an isolated and marginal person who was a conduit to the gods, with her family members interpreting these words for the outside community. Although the authors assert that she fulfilled many of the criteria of shamans, the criteria are not enumerated, and it appears apart from divinatory trances, there are none. How could Veleda have fulfilled shamanic roles of community healing and overnight rituals if she is isolated from everyone? German seers were almost always women, a feature of Mediums. Veleda's prediction of a successful rebellion against the Romans shows she existed in a society with high levels of political incorporation and warfare, features also characteristic of Mediums.

Aldhouse-Green and Aldhouse-Green difficulty in identifying shamans in the archaeological record is compounded without an empirical model of what is a Shaman and how to differentiate them from other kinds of ritualists. The failure to differentiate 
between Shamans and other types of shamanistic healers is obvious in repeatedly equating any evidence of ASC as a sign of shamanism, any animal depiction or bone as a shamanic familiar, any physical deformity as indication of shamans, and any mythological or iconic referent to flight or combined human-animal features as evidence of the presence of a Shaman. Shamanistic themes are found in myth and literature of Europe, but do not establish that practitioners of the era were Shamans. The assertion of shamans performing sacrificial rituals (p. 200) shows how far from shamanism Aldhouse-Green and Aldhouse-Green stray, as sacrifice is not associated with Shamans (nor Shaman/Healers), but with Healers, Mediums, and Priests.

\section{So Where Is the Evidence of Prehistoric Burials of Shamans of Eurasia?}

Mykhailova (2019) reviews prehistoric burials of Eurasia that are interpreted as shamans: "I propose to consider cemeteries with cervid antlers and zoomorphic artefacts ... as relating to 'shamans' in a semiotic way ... I consider only shamans whose major spirit-patron was Deer or Elk. Mostly this spirit-patron was MotherAnimal or Deer-Mother" (pp. 343, 344). "I assume that certain features of cemeteries with antlers demonstrate that they may be 'shaman's' graves. The unusual richness of grave goods (in comparison to those of other graves) . . looks like a feature of 'shaman' burials" (p. 357). But the distribution of deer antler or bones across all graves is never indicated to allow assessment of their relative rarity. Furthermore, the proposal that interments with deer parts are signs of shamans would appear undercut by burial of a dog with red deer antler and flint knives (p. 347).

Mykhailova proposes a shaman burial from the Upper Paleolithic, the Lady of SaintGermain-la-Rivière, a young adult woman found in a disturbed grave, compromising reconstruction. The shaman identification is based on a bison skull and reindeer antlers found nearby, along with a fox mandible that Mykhailova asserts was employed in rebirth rituals for animals, based on ethnographic and archaeological evidence from elsewhere. Another implied shaman burial of a woman with a 3-year-old child found at the Vedbæk-Gøngehusvej 7 burial complex in Denmark had a bird beak near the woman's head. But ethnographic analogies indicate that women are prohibited from shamanizing during childbearing years (Winkelman 1992). A similar Mesolithic burial in Germany of a woman with a little baby between her hips similarly questions the shamanic identity attributed, although such an interpretation is suggested by a "rich inventory [of] roe deer antlers, boar tusks, turtle shell, stone and antler axes, the teeth and jaws of animals, shells, and a drilled bone item (probably a musical instrument)" (p. 348).

Summarizing others, Mykhailova concludes that antlers deposited on top of the burial indicate the deceased's connection with religious activity, based on the association among garment fasteners made of bone pins, flint blades, and antler structures which are significantly associated with graves with richer deposits. But elsewhere Mykhailova notes in other alleged shaman graves that the grave goods were poorer than those found elsewhere (p. 346). How can we know with reliability which graves are of shamans? Mykhailova (2019, p. 357) summarizes Serikov's (2003) findings from Siberian burials identified as shamans, suggesting common features include "burials in caves or under stone slabs; unusual positioning of the deceased (e.g., sitting); deep pits; dismemberment; and bones of animals, birds, or fishes as a detail 
of the costume." However, such features are not all consistently found in even a majority of burials that Mykhailova proposes as containing shamans.

The weakness in Mykhailova's (2019; p. 342) model for identification of features of a shaman is revealed in telling the reader that "Shamanism is a practice that involves a practitioner reaching 'altered states of consciousness' (see Hoffmann 1998)," citing a "Trance Workbook" that teaches people how to use trances to reveal your true self! Mykhailova further proposes "the most important shamanistic feature . . . [is] obsession" (p. 343) without telling us what obsession is except by way of using it with ecstasy, a similarly vague word. The doubt that Mykhailova apparently has about identifying shamans is indicated by occasionally using quotes around "shaman," but exactly why this is done is not clarified. This doubt is expressed in the conclusions, stating "numerous burials with associated zoomorphic characteristics . . . may be interpreted as burials of ritual executors or shamans" (p. 356). But the idea of other types of ritual executors is not explicitly entertained in spite of the author's statement suggesting a different form of religious activity. Mykhailova (2019, p. 341) proposes numerous burial complexes with the same type of animal remains - red deer or roe deer-are likely connected with a deer cult in a "myth-ritual complex. The object of worship is a sacred deer, incarnated as a female deity known as Deer-Mother, who is a . . zooanthropomorphic ancestor . . . connected with the reproduction of deer and with hunting magic ... During those ceremonies, participants dressed as a deer, imitated deer coupling, and then killed and ate the sacral animal and buried its bones and antlers in sacred places for future regenerations of deer" (Mykhailova 2019, p. 341).

While Mykhailova proposes the main participant in these rituals was a shaman, the overall complex of events does not correspond to those of the Forager Shamans derived from the ethnological analysis. An expanded concept of the Shaman might be appropriate for the contexts analyzed by Mykhailova, but deer cults, ancestor worship, and fertility rituals fall outside of the empirically derived features of Shamans. While the ethnological and biosocial models concur in Shamans as ritual specialists in simple societies, they also illustrate two distinct roles of animals as natural symbols and foci of ritual, one related to the individual powers of the shaman and the other to the role of animals as totems - corporate symbols of kinship entities or other groups. In differentiating these, the nature of the animals involved is important, insofar as Shaman's power animals are not typically food species, while animals representing clans and other political groups may be used as foods in Priests' sacrifices (i.e., bulls, pigs, water fowl).

Mannermaa (2008) illustrates these differences in examining the animal bones in human burials sites in Latvia from Middle Neolithic, Mesolithic, and Neolithic periods, and in relationship to the hunter-gatherer ideology of Stone Age and premodern northern Europe. In this context, birds represent the shaman's spirit helpers or guardian spirits and magical flight. The representation of flying can be indicated by the presence of bird wings near the deceased's arms that emphasizes the intention to symbolize flight. However, in assessing the significance of finding the same species of bird in graves across a region, Mannermaa (2008) suggests that the repeated presence of jays represents a groups' totem animal, and that the people interred were important group leaders. Mannermaa questions whether the interred are "leaders or shamans." Obviously, the common use of the same animal suggests clan totemic function, but what are the features associated with bird skeletons that might distinguish a Shaman from a 
Priest? If the same animal appears repeatedly in burials across a region and is widely used for food or raw materials, it is not likely representative of shamanism, but rather clans.

These differences are illustrated in a burial discovered in Hilazon Tachtit in the southern Levant ( $c a$. 15,000-11,600 cal BP) associated with the Natufian culture undergoing the foraging to farming transition. A skeleton and artifacts found there have features which have led to identification of the deceased as a shaman (Grosman, Munro \& Belfer-Cohen 2008). Among the supportive evidence is the identification of a clearly disabled elderly woman with unique burial features. Skeletal evidence indicative of various pathologies causing limping is interpreted by the authors as a sign of shamanic qualities. Although no systematic evidence is presented for shamandisability associations, the ethnological model supports such extensions in finding that Shamans are generally selected following periods of illness.

What attests to the individual's special status and high esteem is the presence of a large number of highly unusual grave goods. These included the bones of a complete articulated human foot that likely reflected the Natufian culture's practices of secondary burial and use of bones as ritual items. One of the most impressive findings was the burial of 50 complete Mediterranean tortoise shells with the woman, along with the limb bones which indicate that entire tortoises were transported to the remote site for feasting. This burial also included parts of bodies of a number of different animals, notable for being unusual on a number of counts. Some of the animals rarely occur in Natufian assemblages, some unusual for being largely complete skeletons, and others for being unbroken bones, a rarity in a society that normally processed bones to extract fat. In addition to the numerous tortoise shells, there were bones not only from food animals such as auroch and wild boar, but also from a golden eagle; two marten; an extremely rare find, a panther; as well as gazelle horn cores, which like the marten, are identified as having spiritual significance for the Natufian in other contexts.

It is in comparative perspective, contrasting the range of grave goods for a society, especially commoner vs. elite differences, that we have the best basis to designate graves of ritualists. In contrast with the emerging practice of the Natufians to routinely bury the deceased within or close to residential areas, this burial was $10 \mathrm{~km}$ from known domestic sites and $150 \mathrm{~m}$ up a steep escarpment, a place of difficult access, especially considering the quantity of grave goods deposited. The findings of grave goods far more numerous than normal and with a much greater diversity than found in other Natufian graves attest to the special nature of this person interred in a location that required considerable effort. Her high status as a Shaman is strongly suggested by the presence of bones of non-food animals with unusual powers, eagles and panther.

However, in broader analysis, the ceremony of her burial was not necessarily a shamanic ceremony of healing, but rather an indication of incipient ancestor worship, indicated by the scale of food available to feed a couple of thousand. The same pattern is revealed by Goring-Morris and Horwitz (2007) who provide evidence of collective ritual activity in an unusual human-faunal deposit in a Neolithic site, the "Bos pit" at Kfar HaHoresh in the Nazareth hills of lower Galilee which presents indications of a celebratory mortuary feast. Among the evidence is the presence of several hundred bones of Bos (cattle), including a total of eight mostly large animals. The bones were intentionally placed together in a large pit in a single event as indicated by the orientation of the majority of the post-cranial bones pointing towards the northwest. 
The occurrence of a large-scale mortuary feast, rather than a votive offering, is attested to by the sheer quantity of the meat derived, exceeding $500 \mathrm{~kg}$ after processing, evidence of a funerary gathering of considerable scale.

Goring-Morris and Horwitz (2007) interpret the lack of skulls and horns of the cattle in the "Bos pit" offering as reflecting practices of "post-depositional removal of human skulls ... interpreted as reflecting an ancestor cult [and that] . . intentional skull removal in animals before burial is undoubtedly associated with the use of animal crania for ritual purposes" (p. 914). That these ritual activities involved a "mortuarycum-cult centre for villages in the region" is supported by widespread evidence of the use of cattle heads as "a favoured taxon for symbolic depictions in statuettes, murals, stone-carvings and bas-reliefs in sites throughout the Near Eastern world" (p. 915).

\section{Transegalitarian Hunter-Gatherer Religions}

A further approach to differentiating the Shaman from other ritualists such as the Priest comes from the ethnological model presented here, which can provide distinctions derived from ecological and political features of the societies (foraging versus agriculture; warfare; hierarchical political integration). Contextual information indicating large settlement size, regional (as opposed to local) political organization, and collective ritual activities of a multi-community scale would also indicate a Priest's activities.

By no means should ancient ritual artifacts of foraging societies be automatically attributed to shamanism. Hayden (2003) points out clear archaeological evidence identifying new religious structures that emerged in transegalitarian societies during the Neolithic. A notable feature is megalithic architecture from which public ceremonies involving a large number of people could be performed. Here, multi-community feasting in lavish bonding rituals linked together males of diverse communities, with beakers and urn grave goods attesting to the importance of elite drinking of alcohol as a mechanism for building solidarity and reinforcing alliances to produce surpluses. Artifacts associated with these structures communicate power and authority in items such as axes, shields, crooks, and staffs. Massive public structures also house secret elite initiations in shrines within lower-levels only accessible from upper-level residential dwellings. The presence of ancestor cults is attested to in animal figures as representative of groups and in the burial of elderly men with elaborate grave goods and offerings, often with their skulls removed and used as ritual objects. These cults had fertility as a central ritual concern, indicated in depictions of pregnant females with rotund bodies and enlarged breasts and buttocks. Such practices appear as the preliminary forms of priesthoods.

\section{Are the Chinese $W u$ Shamans?}

Dambricourt-Malass et al. (2019) analyze the Dahongyan rock paintings in Guizhou, China, including one that they call "The shaman dance," produced by people from an agropastoral culture. They link elements of the frescos to local rituals involving the sacrifice of buffaloes and worship of ancestors for protection of the production of Chinese pearl barley, which they identify in the fresco depictions. They point to shamanic features in representations suggesting dancing masked figures, the presence of drums, and the possible conflation of a snake with human limbs. 
Should these figures be called Shaman? While the authors assert an "association between the dance and the shamanic trance in agro-pastoral cultures is well known in Chinese ethnic minorities," the source they immediately quote suggests different types of religious practitioners - mediums, sorcerers, and witches: "the mediums of folk religion who were able to establish contacts with spirits and gods through trance or demonic possessions. . . . Chinese sources refer to both types of specialists as ' $w u$ ' meaning witch or sorcerer (Seiwert 1987)" (p. 47).

Dambricourt-Malass et al. provide further evidence suggesting it is not a Shaman of which they speak when they characterize the figures as "proceeding in a ritual seasonal dance driving out the hostile spirits, for example from the crops of millet. The Dahongyan dance can be understood as an exorcist ritual" (p. 47). Seasonal agricultural rituals are features of Priests, Healers, and Mediums, not Shamans, and exorcisms typify Healers and Mediums rather than Shamans. Dambricourt-Malass et al. (2019, p. 50) further suggest an identity as a Medium in asserting that: "Contrary to ritual priests, the mediums are quite often females (Seiwert 1987)."

The subsistence and social features of this group provide criteria for these alternate interpretations of the nature of the ritualists depicted here. The authors suggest the depictions represent "an important event such as a peace dialogue between two tribal chiefs, one could be a woman with shamanic power as suggested by the associated animals and a body with strange shapes and proportions" (p. 51). If the society is agricultural and also tribal, which implies a clan structure, this indicates the representation of a clan Priest. The depiction of a female indicates the possibility of an accompanying Medium. So are these figures Shamans or Shaman/ Healers or are they Healers, Mediums, or even Priests? These later identities for these ritualists are illuminated by the history of Chinese religious practitioners called $w u$ in ancient texts.

\section{History of Wu and Its translation as Shaman}

As modern Chinese scholars became aware of Eliade's concept of shamans, some began to translate $w u$ as shaman but without critical assessments of whether it was appropriate (see Keightley 1998 for critique). This attribution of the translation shaman is somewhat surprising in light of Eliade's explicit rejection of such equivalence. Eliade discussed vestiges of China's archaic shamanism in male practitioners $(x i)$, but rejected the association of the shaman with the $w u$, who he characterized as mediums, noting their possession states as an aberrant form of shamanic tradition and reflective of its decadence. Nonetheless, scholars have ignored Eliade's perspective and tended to use shaman in a very loose way to refer to Chinese ritualists.

Williams (2020) reviews studies (von Falkenhausen 1995; Keightley 1998; Boileau 2002) that have shown the error in labeling as shamans these various early Chinese religious practitioners referred to as $w u$. Williams (2020) points out that numerous forms of supernatural practitioners were called $w u$ across the different regions of China, including diviners, spirit mediums, ritual scapegoats, practices involving sorcery and witchcraft, and even some ancient kings and contemporary healing and ancestor ritualists (also see Boileau 2002, pp. 354-355).

Whatever was the original manifestation of this shamanistic form, by the Warring States Period (fifth to third centuries BCE), the term $w u$ was widely used in the 
literature in relation to diverse religious practitioners. The lack of using an objective framework for identifying them as shamans and differentiating them from other religious practices vitiates studies of $w u$ (Keightley 1998). Sukhu (2012) provides an arbitrary and vague justification for translating $w u$ as shaman "as the English academic technical term that is used by mainstream contemporary anthropologists" (p. 75) but insists that "the $w u$ were possessed by spirits," illustrating the problem with arbitrary definitions. The ethnological model presented here has identified cross-cultural patterns that reveal an empirical justification for the concept of the Shaman and distinguishing other types of religious practitioners, enabling the identification of specific characteristics to determine whether such a term can be appropriately applied to a culturespecific phenomenon.

\section{Wu During the Warring States Period}

During the Warring States Period (fifth to third centuries BCE), accounts of $w u$ were well documented because they held positions in the royal courts as advisors to supreme rulers. Cai (2014) and Sukhu (2012) characterize the various functions of the wu paraphrased below to illustrate their features. $W u$ had superhuman abilities that permitted them to communicate with the gods and other spirits who they queried with divinatory procedures and addressed with rituals to assure the well-being of the king and state. The $w u$ appealed to deities through sacrifices and prayers, especially petitioning control of the rains so important for agricultural abundance. A primary function involved numerous forms of divinations, including dream interpretation. $W u$ were predominantly females, with almost all $w u$ referred to in the literature being women. $W u$ were members of an organization (coven) who served the royal court and contributed to bureaucratic and political decisions with divination, but the real source of power was considered to be the possessing male spirit within her. In spite of their employment by the king during the Qin and Han dynasties to make sacrifices and other performances of state religion, the social status of the $w u$ was low. Their ritual techniques involved sacrifices, prayers, incantations, songs, exorcisms, and spells. Their ASC involved possession to engage spirit communication, with the spirit or god descending from heaven upon the person who is possessed by a male spirit. Induction of the ASC involved dancing, incantations, singing, and wailing. A significant service was healing rituals beginning with divination to determine the spirit responsible for a disease and carried out with dances for communicating with spirits. $W u$ performed exorcisms, as well as herbal healing.

It should be apparent that the features of the female $w u$ are more typical of those of the Mediums than those of Shamans by comparing with the features in Tables 1, 2, and 3. $W u$ features notably typical of Mediums and not of Shamans include agricultural rituals, their control by possessing spirits, lower social status, predominantly females, a professional group, propitiation and sacrifices, and healing involving exorcism. Central features of Shamans lacking in the female $w u$ include animal powers and transformation; ASC involving death and rebirth and soul journey; healing of soul loss and extraction of sorcery objects; and use of drumming. Distinguishing ecological and social features of societies typified by Shamans from those of the $w u$ are obvious. In addition to the $w u$ 's presence in an agricultural state-level society with rampant warfare - this was after all the Warring States Period-the Chinese state was 
administered by two competing systems, a centralized bureaucracy and the hereditary aristocracy (Cai), representing the administrators of a system of state-level political integration and the presence of a class system.

Applying this information about the $w u$ and the ethnological model to the depictions in the Dahongyan site might suggest that they represent a Medium and a Priest. But since the Dahongyan site is considered quite ancient (date unknown), earlier forms of the Chinese $w u$ would be a better comparison. Lin (2011) refers to other types of $w u$ he labeled official shamans, commoner or professional shamans, and ancient shamans; the latter would be more appropriate for assessment in terms of the features of the religious practitioners in the Dahongyan rock painting, given the apparent antiquity of the site.

\section{"Ancient Shamans" of the Pre-Quin and Han Period}

Lin (2011) analyzes ancient texts and commentaries to characterize what he refers to as "ancient shamans" of the pre-Quin and Han Period, where the term wu was used for women practitioners, while men who exercised the profession were called xi (also wu xi and $w u y i$ ). The literature of the period regarding them generally refers to activities of males, paraphrased as follows from Lin (2011). These ancient $x i$ had central functions of healing and divining, as well as sacrifices to gods and spirits and rites of ancestor worship, assisting the sovereign in mourning rites. These $x i$ were respected, of high status, exhibiting correct demeanor, loyalty, and trustworthiness, people of superior quality with high intelligence. Their societal power was illustrated in being in charge of religious affairs of the state and enjoying relatively great influence as part of the ruling class. Their rituals involved special sacrificial vessels, vestments and use of statues, animal figures and representations of gods and ghosts, and using sacrifices, and incantations and prayers to gods for blessings. The ancient $x i$ may have engaged in ASC as suggested by their use of visions to illuminate matters and their knowledge of how to "ascend and descend." Their rituals involved preparation with special baths and fasting and ceremonies involving beating the drum, striking the bell, hollering to excite the heart, and "vigorous steps" (dance). The healing functions of $x i$ were considered their most important role, involving use of drugs and plants to drive away pestilence, incantations for removal of illness, and exorcisms and blessings to avert misfortune.

The comparison of these ancient $x i$ with the ethnological model presented here indicates most features are more characteristic of Healers rather than Shamans. Shamans do not perform sacrifices to the gods and spirits nor rites of ancestor worship, while Healers do. The $x i$ 's roles in assisting the sovereign, rituals of state, and their membership in the ruling class are also not characteristic of Shamans (or even Agricultural Shamans), but are characteristic of Healers. The xi's use of ritual objects, incantations, and prayer for healing involving exorcisms and blessings to avert misfortune is typical of Healers, but not Shamans.

Chinese scholars have a tradition of using the word shaman to translate into English the various religious practitioners referred to as different forms of $w u$, but such practices are based on loose analogies, not well-established criteria of what is a Shaman using features with cross-cultural applicability. As Williams (2020, p. 154) notes, "the identification of $w u$ and shaman is problematic [because] . . meanings associated with the term $w u$ actually go far beyond what is suggested by 'shaman' [and] . . comprises almost everybody who has to do with supernatural phenomena." The brief analyses 
here suggest that the female $w u$ should be translated as Medium and the ancient $w u(x i)$, and likely their concomitant official $w u$ and subsequent commoner and professional $w u$ are Healers, not Shaman. Consequently, the figures of the Dahongyan rock art site are likely a Healer (or Priest), and if a female too, then a Medium as well.

\section{The Wugu as a Sorcerer/Witch}

In contrast to the $w u$, who were generally seen as associated with benevolent (white) magic, there was the practitioner referred to in texts as wugu. "Wugu was the art of directing malevolent spirits to harm people" (Cai 2014, p. 146). The wugu performed malevolent magic with the use of poisons and the invocation of evil spirits for personal reasons or to assist others to obtain power and wealth or take revenge against enemies (Cai 2014, p. 146). Inscriptions on oracle bones indicate practices of manipulating various insects and poisonous snakes to produce $g u$ poison and the performance of nighttime rituals involving manipulation of wooden dolls used to represent the intended victims (Cai 2014, p. 146). Accounts of these practices of wugu attest to ritual incantations to cause evil spirits to invade a victim to cause illness and even death. Such practices were prohibited, and people accused were publicly executed.

The importance of witchcraft and execution of witches came to the forefront when the aged and infirmed Emperor Wu accused a royal family of using a (foreign) shaman to perform a curse and manipulation of sorcery dolls to kill him. They were arrested, tried, and the entire family executed. The notion that these practices came from outside of the culture is indicated by the behavior of the prosecutor Jiang who hired shamans alleged to be from Central Asia. These ritualists found the sorcery items, leading to the arrest of suspects who were tortured and put to death (Cai 2014, p. 145). Thousands of royal relatives were executed in a massacre that so decimated the ranks of qualified officials that the Chinese dynasties made a quick conversion to the appointment of Confucian scholars as administrators. This Chinese case of witchcraft executions indicates that the accused may not be just shamanistic healers, but also others with whom they are associated, or thought to be associated by kinship.

\section{A Maya Shaman's Burial?}

In an article on "A Shaman's Burial ...” Prüfer and Dunham (2009) report the finding of a remote Early Classic Maya burial cave featuring the decapitated body of a male whose cranium had been replaced with a ceramic jar, with the skull placed next to the body. The reverential treatment of the deceased was indicated by the interment of grave goods for the afterlife and treatment appropriate for a religious specialist or a member of the elite. But the remains were sealed behind a wall of masonry at a remote location many miles from known pre-Columbian settlements. Prüfer and Dunham (2009) try to explain this remote location by suggesting that the early Classic settlers were recent to the region and distant from their ancestors, and consequently had to resort "to interring the remains of their elites or shamans in caves" (p. 314).

So elite or shaman? Why the doubt? And if an elite, is it a Priest? Or is there another possibility? Prüfer and Dunham (2009) suggest that shamanic features are indicated by sacred bundles, death figures, and zoomorphic depictions exemplified in some unusual vessel iconography recovered with a bird-like image present in the interior of the 
vessel. The depiction seems to conflate the features of avian, reptilian, and aquatic species, suggesting shamanic ideology, but the vessel also contains depictions of several known Maya deities which are often represented as an amalgamation of a human form with that of an animal. They propose the interred individual is a shamanic figure based on contextual analysis of the burial site and the items included, combined with local ethnohistorical data describing the religious practitioners of the Maya.

But while the authors use the term shaman, the sources cited for their justification through ethnographic analogy actually refer to a priest. Describing a seventeenth century account of ceremonies involving stools such as found in the burial, Prüfer and Dunham (2009, p. 307) refer to a "priest [who] sat on a small stool officiating at a ceremony to anoint and cleanse children." Prüfer and Dunham (2009) suggest this alternative interpretation as well, speculating that the primary motivation behind this reverential mortuary practice could have involved ancestor worship since the Mayas considered caves to connect the living and the dead, a location for negotiating relationships with the ancestors in the afterlife. The Early Classic Maya used caves for ancestor worship and even exerted considerable labor to modify them with impressive architectural structures in prominent places as signs of elite power and their control of supernatural forces. However, caves are also associated with sorcery among the ancient and contemporary Maya, so the question of what kind of practitioner remains ambiguous: a Healer, a Priest, or even a Sorcerer/Witch?

The hypothesis of a Priest is undermined by Prüfer and Dunham in noting that even if the interred individual was a powerful person, such remote location indicates that the burial was not for commemoration or worship, but a one-time private mortuary ritual. Furthermore, the remote location and small cave space that could only accommodate a few people do not support collective ancestor worship and the sealed cave indicates that there was no further interaction with the remains of the decease.

Prufer and Dunham propose the interred individual was a feared religious specialist whose post-mortem decapitation and confinement to a remote and sealed cave was to protect the living from his powers. Such features do not support ancestor worship or Priests. Caves are not typically mortuary spaces among the Maya, who instead consider caves to be dangerous places where sorcerers ( h'ak' charnel h'ilol) go to perform rituals that cause harm (Prüfer 2005). Prüfer and Dunham (2009, p. 312) report contemporary Maya believe that these practitioners "invoke spells that cause illness," act as "throwers of illness," and sometimes sell the victim's "inner soul" to an underworld god.

While such practices also may be consistent with shamanism, several factors further suggest this religious practitioner is not a Shaman (nor Shaman/Healer, Agricultural Shaman). Ethnographic analogy from the Tzeltal Maya suggests this is a Sorcerer/ Witch since those suspected of being witches may have their head removed following their killing, a practice that was thought to neutralize their continued exercise of supernatural power following death.

What does the ethnological model suggest? Since the Classic Maya were complex agriculturalists with hierarchical political structures and warfare, the practitioner is likely not a Shaman but a Healer. The identity as a Sorcerer/Witch is also consistent with the subsistence and political profile of the Early Classic Maya (A.D. 250-600) who had a hierarchical government system that was ruled by kings and administered by priests who lived in the large urban ceremonial centers supported by extensive rural 
agriculture. These social factors combined with the remote location of the burial and no evidence of ancestor worship or use as a healing shrine indicate that this practitioner be considered someone who was executed as a Sorcerer/Witch and then respectfully interred by his relatives far from the community out of fear of his power or the desecration of his grave.

\section{Were There Shamans at Casas Grandes?}

Paquimé was the heart of the Casas Grandes culture, influencing the area from contemporary northern Mexico up into the American Southwest and east to west from Texas to Arizona. Its massive influence is evidenced in its striking polychrome pottery diffused across this region between the thirteenth and fifteenth centuries CE. Unique features of Paquimé culture, the most politically complex of the region, included large aggregated communities, massive public architecture, and a social hierarchy based on hereditary leadership which dominated the region during the Medio period (A.D. 1200-1450) (VanPool \& VanPool 2016; VanPool $2003 \mathrm{a}, \mathrm{b}$ ). Images on pottery attest to its distinct cosmological system and beliefs in ritual interactions with supernatural creatures, particularly horned serpents for rain and other rituals for agricultural fertility essential to the survival of this desert culture. The unique function of Paquimé as a regional pilgrimage center for uniting dispersed populations is attested to by the monumental ceremonial architecture and numerous platform mounds that confirm the importance of collective ritual activity (VanPool 2003a). Earlier researchers (Di Peso 1974 cited in VanPool and VanPool 2007) proposed the presence of both shamans and priests. In the Medio Period, ritualists of the Quetzalcóatl cult-controlled religion, economic production, trade, education, and virtually all aspects of Paquimé public life.

VanPool and VanPool's (2007, 2016), VanPool (2003a, b, 2009) analyses of the Paquimé religious system argue that it was shamans, or shaman-priests, that were the central force of this regional culture. They propose that these Paquimé cult ritualists who smoked tobacco, perhaps laced with datura or peyote, were shamans, based on analyses of the symbolic content of vessel imagery and the context of caches. While recognizing that institutionalized leadership at Paquimé involved priests, they nonetheless refer to them as shamans and shaman-priests. But were the Paquimé cult ritualists Shamans as identified in Winkelman's cross-cultural research, or were they Priests with atypical ASC? Or do these practitioners constitute an anomaly that justifies the notion of a hybrid shaman-priest ritualist?

\section{Evidence for Shamans at Paquimé}

The presence of shamans was determined through analysis of Casas Grandes pots with a special symbol - the pound sign symbol (also with small isolated circles) — which is exclusively associated with male effigies, smoking images and items, dancers wearing richly adorned feathered headdress, and various anthropomorphs (VanPool 2003b, p. 703). This co-occurrence of the \# symbol with kneeling figures, smokers, and dancers adorned with headdresses indicates they represent the same group. VanPool (2003a) analyzes images indicating that these ritualists that smoked tobacco entered the "classic shamanic journey" - transforming into supernatural entities 
represented by the feathered serpent and another diamond-shaped deity featuring two macaw heads.

These Paquimé ritualists are represented with serpent symbolism (serpent bands and horned or plumed headdresses) also found on elite burial urns. This association of serpents with elite burials, as well as with ritual vessels with shamanic imagery and paraphernalia found in the House of the Walk-in Well, indicates the association of these ritualists with the Paquimé institutionalized elite class (VanPool 2003b). The presence at the House of the Walk-in Well of caches of pipes, smoker effigies, copper bells, shell noise makers, and pieces of quartz, together with their distinctive pottery, constitutes an "iconic family" identifying this Paquimé cult institution directly concerned with water and agricultural rejuvenation.

Burial items indicate Paquimé elites acquired West Mexican prestige goods and perhaps sacred ritual practices and knowledge that provided the basis of a prestige economy and their political power (VanPool 2003a). Paquimé's valuable artifacts (seashell ornaments and copper bells) from West Mexico suggest their ritual origins are in Mesoamerican political systems, not regional systems such as the Pueblo. Paquimé's Mesoamerican religious influences are seen in morphologically similar ball courts, possibly human sacrifice, and the worship of the gods Quetzalcóatl and Tláloc in rituals for water and agricultural productivity (VanPool \& VanPool 2016, p. 39). The horned or feathered serpent at Paquimé resembles Quetzalcóatl traditions of Mesoamerican groups and its significance is indicated by its presence on ceremonial headdresses and the impressive Mound of the Serpent, a 100+ $\mathrm{m}$ long dam that controlled water for Paquimé.

VanPool (2003b, p. 697) argues that shamans were political leaders in New World societies and that "recent iconographic analyses have demonstrated that shamanic priests/leaders are a fundamental component of New World chiefdoms and state-level societies, including the Aztec (Dobkin de Rios 1976: p. 34; Winter 2000: pp. 265, 298)." Since the Aztec had Mesoamerican ritual patterns prominently featured at Paquimé, their characteristics are relevant to interpretation of Paquimé ritual specialists.

But what do de Rios and Winter say about these Aztec ritualists? Neither de Rios nor Winter provides any iconographic analyses regarding the Aztecs on the pages cited or elsewhere in these publications. De Rios (1976) does note that "shamanistic religious elements of control and manipulation of the supernatural persisted in state societies such as the Aztecs" (p. 34) but labels the Aztec practitioners as diviners, sorcerers, clergy, hierophants, and priests, explicitly contrasting them with shamans (pp. 34-35). She attributes Aztec use of psychedelic morning glory seeds to ritualists called sorcerers, priests, priestess, and witches, noting their use for divination of causes of disease, interpreting the deities' wishes and performing rites to propitiate them. De Rios refers to the supernatural practitioner who heals as a diviner, one who used psychoactive plants to discern and cure illness and predict the future. In the second edition, de Rios (1984, p. 145) again asserts that the "sacred plants were used most regularly by sorcerers and . . . a highly specialized priest class." The sorcerer (ticitl) used various psychedelics to enter prolonged and profound alterations of consciousness lasting days to carry out diagnostic (divinatory) and healing functions. But neither edition of de Rios' book characterizes any Aztec ritualist as a shaman, nor addresses their roles as political leaders, nor even discusses iconographic analyses or offers 
evidence that VanPool asserts show Aztec shamans as state-level political leaders. Winter does note that among the Aztecs "some priests also served as shamans" (p. 298) and that "one priesthood-that of Cihuacoatl, the earth goddess [likely] . . evolved from an earlier tobacco society, and before that from tobacco shamanism" (p. 268). But Winter also clearly distinguishes the Aztec priests from shamans, stating "There is no mistaking the difference between shamans and priests ... among the Aztec, since Aztec priests were elite, full-time religious functionaries who dedicated their entire lives to their gods" (pp. 292-293). "Aztec priests . . . served as intermediaries between the inhabitants of the Aztec empire and the gods of the supernatural world. . . . In contrast to shamans, they usually did not enter trances, ... There were also true Aztec shamans [ticitl] who used tobacco and other hallucinogens to cure and to predict the future" (p. 298).

Of course, the actual activities and characteristics of these ritualists are more important than what people might label them. The sample used in Winkelman's cross-cultural studies included the Aztecs, whose practitioners were classified in the following types:

Shaman/Healer - the tlapouhqui and ticitl, referred to as fortune tellers, doctors, soothsayers, medicine men, and healers;

Priest - the Aztec sacrificial priesthood, which in spite of their psychoactive ASC were still empirically clustered with the Priest; and

Sorcerer/Witch-Naualli, tetlachiuiana, and tlacatecolot referred to as magician, witch, and wizard.

Another society in the sample was the Zuni, a Pueblo group at the periphery of the Casas Grandes sphere of influence. The Zuni have exactly the same configuration of practitioners as the Aztecs:

Shaman/Healer - theurgist, medicine man, doctor;

Priest_pekwin (sun Priest), apilashiwanni (bow Priests), katcina, and ashiwanni (rain Priest), all virtually identical in selection through social inheritance and political appointment; rituals for agricultural well-being; and serving under the leadership of the pekwin, who directs the annual rituals; and

Sorcerer/Witch-sorcerer or witch, for which no indigenous term was given in sources consulted.

This empirically derived evidence regarding practitioner types suggests that the Paquimé culture should have had the following: a Priest, with empirical characteristics of Priests in spite of the drug-induced ASC; a distinct practitioner representing the shamanistic healer; and perhaps a Sorcerer/Witch. The findings suggest that if there is a Shaman at Paquimé, it is likely a Shaman/Healer (Agricultural Shaman) primarily functioning as a healer, not these elite cult specialists with Mesoamerican origins. These Shaman/Healers are indicated in artifacts (drums, figurines, and crystals) from the Viejo period. This activity would have occurred in idiosyncratic locations and without apparent patterns, a phenomenon reflective of ritual practices of shamans (Rakita 2009). 
So, what type of religious practitioners are these Paquimé ritualists? The evidence that VanPool presents for labeling them as shamans comes from reconstruction of archaeological data which indicates the following characteristics of these ritualists:

- ASC Induction

- Males' smoking pipes in odd stances indicative of ritual dancing

- Shamanic cache (pipes, quartz, fetishes, copper bells) in House of the Walk-inWell

- $\quad$ Tobacco use evidenced by regional use and pipe and pipe iconography

- ASC Experiences

- Checkerboard collars, "zigzag" body morphology, and other geometrics indicative of entopic imagery

- Bird image on top of leg suggesting flight and spirit travel

- Macaw-headed anthropomorphs depicted horizontally suggesting soul flight

- Anthropomorph flying with a tutelary bird on leg

- Animal Relations

- Association with serpent imagery and birds

- Figures with serpent headdresses

- Shamanic transformation from human to spirit to macaw

These features above are all consistent with the ethnological profile of a Shaman, but there are many other characteristics of Paquimé cult ritualists that the VanPools present that are not typical of Shamans or Shaman/Healers, but of Priests, as follows:

Selection and Training: social inheritance, hierarchy based on hereditary leadership

Magico-Religious Activity: rituals for rain, agricultural fertility, worship of high gods Motive and Context: collective social rituals in public places, calendrical agricultural rites

Social Characteristics: social, economic, political, and religious elite; powerful elite priesthood, exclusively male

Sociopolitical Power: highest leaders, most politically complex system of region, warfare

Professional Characteristics: hierarchically organized group based on kinship

Supernatural Power and Control of Power: high gods - rain and agricultural gods, horned/plumed serpent and macaws; ancestor worship; direct contact with and transformation into god

Ritual Techniques: collective public rituals, sacrifices

Apart from the ASC features and animal relations, all of the features that have been adduced for the Paquimé ritualist pertain to Priests, not Shamans. Furthermore, this Paquimé ritualist lacks documentation of most of the empirical features of Shamans. Since the Paquimé cult ritualist have traditions that came from outside of the region and brought in a cult of priestly practices, it seems unlikely that they had the other features of Shamans in spite of the druginduced ASC. The Paquimé ritualists' combination of the priestly role with significant ASC is unusual but is consistent with their hypothesis that shamanistic practices and even Shamans may play a role in the social evolution of Priests. In Winkelman's SCCS 
subsample, the Marquesan Inspirational Priest undergoes training similar to the shaman's vision quest and the Creek Fire Priest was required to be a shaman as well. Priests in simple societies appear to have greater engagement with ASC, which declines with increasing political integration $(r=-.46 ; p<.004$; Winkelman 1992).

Whether these Paquimé elite ritualists are shamans or not obviously depends on one's concept of shamans. One of VanPool's (2009, p. 179) definitions of shamanism is "a religious system in which individuals work for their people by directly interacting with the spirit world," criteria that fails to distinguish shamans from virtually any religious practitioner. Elsewhere, VanPool (2003b, p. 696) suggests that "Shamans, commonly defined as intermediaries between the 'natural' and 'super-natural' worlds, communed with the supernatural through ritual and ecstatic trances to gain help and knowledge for healing, weather manipulation (e.g., rain seeking), divination, ensuring successful hunts, finding lost objects, self-empowerment, killing enemies, or other important activities such as ensuring fertility and fecundity for the benefit of their people." Most of these alleged characteristics of shamans, as well as those derived from the ethnological research reported here, have not been established for the Paquimé ritualists.

VanPool's (2009) efforts to identify the nature of the Paquimé ritualist are undermined by the notion that categories such as shaman should be defined, rather than discovered; the ethnological approach is the opposite - we discover patterns (derived etics) rather than impose interpretive frameworks in defining the data. Arbitrary selections of features do not enable identification of shamanism if it is an empirical phenomenon, as this ethnological research has shown. VanPool and VanPool (2015, p. 91) propose the Paquimé ruling cult system was introduced during the Medio Period "from Mesoamerican sources (in this case the Aztatlan system) through direct contact and was used by elite shaman-priests to establish and maintain their authority." This outside source and many features of the Paquimé system suggest that these influences involved secret societies or sodalities as described by Hayden (2018).

\section{Conclusions: Sociocultural Evolution of Religion}

The features of religious practitioner presented here provide a multi-faceted interpretive tool to enhance interpretation of the past, both through using social and ecological features established by cross-cultural research to infer the presence of specific types of religious practitioners in the past, as well as using the biogenetic model to infer the nature of religious practice and belief.

The evolutionary sequence of practitioner types presented here is based on the empirically established relationships to subsistence types and political conditions. If these empirically identified social complexity features of a society are known, then the religious practitioners likely present and their characteristics can be imputed. If unique identifying features of a religious practitioner type are available in artifactual data, then the fuller profile of the practitioner can be inferred from this ethnological analogy.

These selection-function relations discovered here implicate biogenetic bases of religion; these manifestations are affected by ecological adaptations and sociopolitical conditions, and most notably varying as a function of subsistence patterns and political integration. The findings presented above indicate that these three biogenetic foundations for religious practices involve: 
1. Shamanistic healers that use alterations of consciousness in communal rituals for divination and eliciting endogenous healing responses;

2. Priests selected through social inheritance who use kinship-based principles for producing hierarchical political organization and perform collective rituals for agricultural abundance and propitiation of communal high gods for general protection; and

3. A Sorcerer/Witch, selected by social labeling processes involving religious authorities who attribute to them the qualities of an exclusively immoral agent, using ingroup versus out-group moral dualism for persecution of socially defined outgroups.

A cultural universal and universal of religion involves the use of ASC in healing, which takes different forms depending on subsistence and political complexity. The differential relationships of ecological and social conditions to specific shamanistic practitioner types reflect effects of specific kinds of social conditions. These biological aspects of religion are manifested in a human universal, the presence of ritual alterations of consciousness for healing. Even when practitioners no longer engage the obvious alterations of consciousness characteristic of Shamans, they still primarily are concerned with healing.

A social universal is provided by the Priests and their agricultural rituals and worship of common gods; while their deep basis undoubtedly comes from adaptive biological biases creating preferences for the patterns of behaviors of one's ancestors, the manifestation of this biological impulse as a religious practitioner depends on the ecological and social conditions produced by intensive agriculture and political integration. Hence, Priests are a social universal of those types a society, but not a cultural universal. This second phase and level of cultural evolution of religious practice appears to involve the elevation of ancestor worship into society-wide cults first emerging under conditions of abundant resources that allow complex hunter-gatherers to create a new level of ritual activity based on clan totemism. These developments into Priests under conditions of intensive agriculture meet needs for agricultural coordination and hierarchical political integration.

These distinctive bases for religious practitioners provide an understanding of the persistent distinctions noted by generations of comparative religion scholars, perhaps none more central than the distinction between magic (Shamans and other shamanistic healers) and religion (Priests), with the latter producing the context of the conflict between the moral order and evil, creating the Sorcerer/Witch. Thus, the figures of the Shaman, Priest, and Sorcerer/Witch reflect, respectively, ritually induced endogenous healing practices; kinshipbased systems for social control of agriculture and political integration in societies; and social conflict produced by hierarchical political subordination of people with competing local-level religious practices.

Acknowledgements Many thanks to Todd VanPool for his generous assistance in locating materials relevant to Paquimé and interpretation of their culture. The author of this article has full responsibility for the conclusions drawn from that material. Thanks to the reviewers for their helpful suggestions in improving this article.

Funding The author received a National Science Foundation Dissertation Improvement Grant for coding reliability checks on the updated variables and data referenced here. 
Data Availability The religious practitioner type and social data used here are available in the CosSci program housed at the University of California, Irvine; see http://socscicompute.ss.uci.edu/. The original dataset used to derive these practitioner types has been updated, expanded, and subjected to coding reliability checks. This unanalyzed revised dataset is available through the author's page under projects at www. researchgate.net and at the Mendeley data repository at https://data.mendeley.com/datasets/34pjbr4kg4/2.

\section{Declarations}

Conflicts of interest The author declares no competing interests.

Open Access This article is licensed under a Creative Commons Attribution 4.0 International License, which permits use, sharing, adaptation, distribution and reproduction in any medium or format, as long as you give appropriate credit to the original author(s) and the source, provide a link to the Creative Commons licence, and indicate if changes were made. The images or other third party material in this article are included in the article's Creative Commons licence, unless indicated otherwise in a credit line to the material. If material is not included in the article's Creative Commons licence and your intended use is not permitted by statutory regulation or exceeds the permitted use, you will need to obtain permission directly from the copyright holder. To view a copy of this licence, visit http://creativecommons.org/licenses/by/4.0/.

\section{References}

Aldhouse-Green, M., \& Aldhouse-Green, S. (2005). The quest for the shaman. Shape-shifters, sorcerers and spirit-healers of ancient Europe. Thames \& Hudson.

Bever, E. (2008). The realities of witchcraft and popular magic in Early Modern Europe. Palgrave.

Boileau, G. (2002). Wu and Shaman. Bulletin of the School of Oriental and African Studies, 65(2), 350-378.

Bourguignon, E., \& Evascu, T. (1977). Altered states of consciousness within a general evolutionary perspective: A holocultural analysis. Behavior Science Research, 12(3), 197-216.

Boyer, P. (2019). Informal religious activity outside hegemonic religions: Wild traditions and their relevance to evolutionary models. Religion, Brain and Behavior, 10(4), 459-472. https://doi.org/10.1080/ 2153599X.2019.1678518.

Cai, L. (2014). Witchcraft and the rise of the first Confucian empire. State University of New York Press.

Clottes, J., \& Lewis-Williams, D. (1998). The shamans of prehistory trance and magic in the painted caves. Harry N. Abrams.

Craffert, P. (2008). The life of a Galilean shaman: Jesus of Nazareth in Anthropological-Historical Perspective. Cascade.

Dambricourt-Malass, A., Cao, B., You, Q., \& Zhang, P. (2019). Agro-pastoral rituals and shaman dances of Dahongyan rock painting, Guizhou, Southwestern China, new investigations. Quaternary International, 507(25), 43-52. https://doi.org/10.1016/j.quaint.2018.12.011.

Davies, S. (2015). Spirit possession and the origins of Christianity. Bardic Press.

De Rios, M. (1976). The wilderness of the mind: Sacred plants in cross-cultural perspective. Sage.

De Rios, M. (1984). Hallucinogens: Cross-cultural perspectives. University of New Mexico Press.

Di Peso, C. (1974). Casas Grandes: A fallen trading center of the Gran Chichimeca. Amerind Foundation.

Dixon, W., \& Brown, M. (1979). Biomedical computer programs P-series. University of California.

Dunbar, R. (2014). Human Evolution: A Pelican Introduction [Kindle iOS version]. Retrieved from https:// www.Amazon.com.

Dunbar, R. (2017). What's missing from the scientific study of religion? Religion. Brain and Behavior, 7(4), 349-353. https://doi.org/10.1080/2153599X.2016.1249927.

Durkheim, E. (1915). The elementary forms of religious life. George Allen and Unwin.

Eliade, M. (1964). Shamanism: Archaic techniques of ecstasy. Pantheon Books. Originally published as Le Chamanisme et les techniques archaïques de l'extase (Paris: Librairie Payot, 1951).

Elkin, A. P. (1978). Aboriginal men of high degree. St. Martin's Press.

Ember, C. (1975). Residential variation among hunter-gatherers. Behavior Science Research, 10(3), $199-227$.

Ember, M., \& Ember, C. R. (1995). Worldwide cross-cultural studies and their relevance for archaeology. Journal of Archaeological Research, 3, 87-111 https://doi-org.ezproxy1.lib.asu.edu/10.1007/BF02231488. 
Ensor, B., Irish, J., \& Keegan, W. (2017). The bioarchaeology of kinship? Proposed Revisions to assumptions guiding interpretation. Current Anthropology, 58(6), 739-761. https://doi.org/10.1086/694584.

Goring-Morris, N., \& Horwitz, L. (2007). Funerals and feasts during the pre-pottery Neolithic B of the Near East. Antiquity, 81, 902-919.

Gower, J. (1971). A general coefficient of similarity and some of its properties. Biometrics, 27, 857-874.

Grosman, L., Munro, N., \& Belfer-Cohen, A. (2008). A 12,000-year-old shaman burial from the southern Levant (Israel). PNAS, 105(46), 17665-17669. https://doi.org/10.1073/pnas.0806030105.

Hayden, B. (2003). Shamans, sorcerers, and saints: A prehistory of religion. Smithsonian Books.

Hayden, B. (2018). The power of ritual in prehistory: Secret societies and origins of social complexity. Cambridge University Press.

Hultkrantz, A. (1973). A definition of shamanism. Temenos, 9, 25-37.

Jakobsen, M. (1999). Shamanism: Traditional and contemporary approaches to the mastery of spirits and healing. Berghahn Books.

Jones, P. (2008). Shamanism: An inquiry into the history of the scholarly use of the term in English-speaking North America. Anthropology of Consciousness, 17(2), 4-32. https://doi.org/10.1525/ac.2006.17.2.4.

Kahn, J. (2015). Identifying residences of ritual practitioners in the archaeological record as a proxy for social complexity. Journal of Anthropological Archaeology, 40, 59-81. https://doi.org/10.1016/j.jaa.2015.06.001.

Keightley, D. (1998). Shamanism, death, and the ancestors: Religious mediation in Neolithic and Shang China (ca. 5000-1000 B.C.). Asiatische Studien, 52(3), 763-831.

Kelly, R. (2013). The lifeways of hunter-gatherers: The foraging spectrum. Cambridge University Press.

Launay, J., Tarr, B., \& Dunbar, R. (2016). Synchrony as an adaptive mechanism for large-scale human social bonding. Ethology, 122(10), 779-789. https://doi.org/10.1111/eth.12528.

Lewis-Williams, D. (2002). The mind in the cave: Consciousness and the origins of art. Thames and Hudson.

Lin, F.-S. (2011). The image and status of shamans in ancient China. In J. Lagerwey \& M. Kalinowski (Eds.), Early Chinese religion; part one: Shang through Han (1250 BC-220 AD) (4th ed., pp. 397-458) Handbook of Oriental Studies.

Mandell, A. (1980). Toward a Psychobiology of Transcendence: God in the Brain, in D. Davidson and R. Davidson, eds, The Psychobiology of Consciousness. New York: Plenum, 379-464.

Mannermaa, K. (2008). Birds and burials at Ajvide (Gotland, Sweden) and Zvejnieki (Latvia) about 80003900 BP. Journal of Anthropological Archaeology, 27, 201-225.

Murdock, G., \& Provost, C. (1973). Measurement of cultural complexity. Ethnology, 12, 379-392.

Murdock, G., \& White, D. (1969). Standard cross-cultural sample. Ethnology, 8, 329-369.

Mykhailova, N. (2019). Shaman' burials in prehistoric Europe. Gendered images? In J. Koch \& W. Kirleis (Eds.), Gender transformations in prehistoric and archaic societies (pp. 341-362). Sidestone Press.

Ostorero, M. (2019). Witchcraft. In S. Page \& C. Rider (Eds.), The Routledge history of medieval magic (pp. 502-522). Routledge/Taylor and Francis.

Palmer, C., Ellsworth, R., \& Steadman, L. (2009). Talk and tradition: Why the least interesting components of religion may be the most evolutionarily important. In E. Voland \& W. Schiefenhövel (Eds.), The biological evolution of religious mind and behavior (pp. 105-116). Springer Verlag.

Peoples, H., Duda, P., \& Marlowe, F. (2016). Hunter-gatherers and the origins of religion. Human Nature, 27(3), 261-282. https://doi.org/10.1007/s12110-016-9260-0.

Peregrine, P. (2004). Cross-cultural approaches in archaeology: Comparative ethnology, comparative archaeology, and archaeoethnology. Journal of Archaeological Research, 12(3), 281-309. https://doi.org/10. 1023/b:jare.0000040232.61243.89.

Peters, L., \& Price-Williams, D. (1981). Towards an experiential analysis of shamanism. American Ethnologist, 7, 398-418.

Previc, F. (2009). The dopaminergic mind in human evolution and history. Cambridge University Press.

Prüfer, K. M. (2005). Shamans, caves and the roles of ritual specialists in Maya society. In J. E. Brady \& K. M. Prüfer (Eds.), The maw of the earth monster: Mesoamerican ritual cave use (pp. 186-222). University of Texas Press.

Prüfer, K. M., \& Dunham, P. (2009). A shaman's burial from an early classic cave in the Maya Mountains of Belize. Central America World Archaeology, 41(2), 295-320. https://doi.org/10.1080/ 00438240902844236.

Rakita, G. F. M. (2009). Ancestors and elites: Emergent complexity and ritual practices in the Cases Grandes polity. AltaMira.

Sar, V. (2017). Parallel-distinct structures of internal world and external reality: Disavowing and re-claiming the self-identity in the aftermath of trauma-generated dissociation. Frontiers in Psychology, 8, 216. https:// doi.org/10.3389/fpsyg.2017.00216. 
Sar, V., \& Ozturk, E. (2007). Functional dissociation of the self: A sociocognitive approach to trauma and dissociation. Journal of Trauma \& Dissociation, 8(4), 69-89. https://doi.org/10.2139/ssrn.2462391.

Schachter, S. (2006). Religion and the brain: Evidence from temporal lobe epilepsy. In P. McNamara (Ed.), Where God and science meet: How brain and evolutionary studies alter our understanding of religion (Vol. 2, pp. 171-188). Praeger.

Seiwert, H. (1987). On the religions of national minorities in the context of China's religious history. In T. Heberer (Ed.), Ethnic minorities in China: Tradition and transformation (pp. 41-51). Herodot/Rader Verlag.

Sered, S. (1994). Priestess, mother, sacred sister. Oxford University Press.

Serikov, J.B. (2003). Shamanskiie pohrebeniia kamennoho veka. In Ėtnografoarkheologicheskie kompleksy: Problemy kul'tury i sotsiuma 6 (pp. 141-164). Novosibirsk: Nauka. (cited in Mykhailova).

Siikala, A. (1978). The rite technique of Siberian shaman. Folklore fellows communication 220. Soumalainen Tiedeskaremia Academia.

Spencer, B., \& Gillen, F. J. (1899). The native tribes of central Australia. Macmillan and Co., Ltd..

Steadman, L., Palmer, C., \& Tilley, C. (1996). The universality of ancestor worship. Ethnology, 35, 63-76.

Sukhu, G. (2012). The shaman and the heresiarch: A new interpretation of the Li Sao. State University of New York Press.

Václav, H., Pavel, D., Šaffa, G., Květina, P., \& Zrzavy, J. (2020). Identifying post-marital residence patterns in prehistory: A phylogenetic comparative analysis of dwelling size. PLoS One, 15(2), e0229363. https://doi. org/10.1371/journal.pone.0229363.

VanPool, C. S. (2003a). The symbolism of Cases Grandes. University of New Mexico.

VanPool, C. S. (2003b). The shaman-priests of the Casas Grandes region, Chihuahua, Mexico. American Antiquity, 68, 696. https://doi.org/10.2307/3557068.

VanPool, C. S. (2009). The signs of the sacred: Identifying shamans using archaeological evidence. Journal of Anthropological Archaeology, 28, 177-190. https://doi.org/10.1016/j.jaa.2009.02.003.

VanPool, C. S., \& VanPool, T. L. (2007). Signs of the Cases Grandes shamans. University of Utah Press.

VanPool, C. S., \& VanPool, T. L. (2015). Religion and cosmology in the Cases Grandes world. In P. E. Minnis \& M. E. Whalen (Eds.), Ancient Paquime and the Casas Grandes world (pp. 83-102). University of Arizona Press. https://doi.org/10.2307/j.ctt183p9cj.8.

VanPool, C. S., \& VanPool, T. L. (2016). Serpents from sky to water: Cases Grandes religion and leaders. In P. E. Minnis \& M. E. Whalen (Eds.), Discovering Paquimé (pp. 37-40). University of Arizona Press.

VanPool, T. L., VanPool, C. S., \& Phillips Jr., D. A. (2006). The Cases Grandes and Salado phenomena: Evidence for a religious schism in the greater southwest. In C. S. VanPool, T. L. VanPool, \& D. A. Phillips Jr. (Eds.), Religion in the pre-hispanic southwest (pp. 235-252). AltaMira Press.

von Falkenhausen, L. (1995). Reflections on the political role of spirit mediums in early China: The wu officials in the Zhou Li. Early China, 20, 279-300.

Whitehouse, H., François, P., Savage, P. E., \& Currie, T. E. (2019). Complex societies precede moralizing gods throughout world history. Nature, 568, 226-229. https://doi.org/10.1038/s41586-019-1043-4.

Williams, N. (2020). Shamans, souls, and soma: Comparative religion and early China. Journal of Chinese Religions, 48(2), 147-173.

Winkelman, M.J. (1985). A cross-cultural study of magico-religious practitioners. Ph.D. diss. University of California, Irvine. Ann Arbor, Mich. University Microfilms.

Winkelman, M. J. (1986a). Magico-religious practitioner types and socioeconomic analysis. Behavior Science Research, 20(1-4), 17-46.

Winkelman, M. J. (1986b). Trance states: A theoretical model and cross-cultural analysis. Ethos, 14(2), 174-203.

Winkelman, M. J. (1990). Shaman and other "magico-religious healers": A cross-cultural study of their origins, nature, and social transformation. Ethos, 18(3), 308-352.

Winkelman, M.J. (1992). Shamans, priests, and witches. A cross-cultural study of magico-religious practitioners. Anthropological research papers \#44. Arizona State University.

Winkelman, M. J. (1998). Aztec human sacrifice: Cross-cultural assessments of the ecological hypothesis. Ethnology, 37(3), 285-298.

Winkelman, M. J. (2002a). Shamanism and cognitive evolution. Cambridge Archaeological Journal, 12(1), 71-101. https://doi.org/10.1017/S0959774302000045.

Winkelman, M. J. (2002b). Shamanic universals and evolutionary psychology. Journal of Ritual Studies, $16(2), 63-76$.

Winkelman, M. J. (2008). Culture and health: Applying medical anthropology. Jossey Bass/Wiley Publishers.

Winkelman, M. J. (2009). Shamanism and the origins of spirituality and ritual healing. Journal for the Study of Religion, Nature and Culture, 34(4), 458-489. https://doi.org/10.1558/jsrnc.v3i4.458. 
Winkelman, M.J. (2010a). Shamanism: A biopsychosocial paradigm of consciousness and healing. Santa Barbara, CA: ABC-CLIO (Second Edition).

Winkelman, M. J. (2010b). The shamanic paradigm: Evidence from ethnology, neuropsychology and ethology. Time and Mind: The Journal of Archaeology, Consciousness and Culture, 3(2), 159-182. https://doi.org/10.2752/175169610X12632240392758.

Winkelman, M. J. (2011a). A paradigm for understanding altered consciousness: The integrative mode of consciousness. In E. Cardeña \& M. J. Winkelman (Eds.), Altering consciousness multidisciplinary perspectives. Volume 1: History, culture and the humanities (pp. 23-44). Preager ABC-CLIO.

Winkelman, M. J. (2011b). Shamanism and the alteration of consciousness. In E. Cardeña \& M. J. Winkelman (Eds.), Altering consciousness multidisciplinary perspectives. Volume 1: History, culture and the humanities (pp. 159-180). Preager ABC-CLIO.

Winkelman, M. J. (2013a). The integrative mode of consciousness: Evolutionary origins of ecstasy. In T. Passie, W. Belschner, \& E. Petrow (Eds.), Ekstasen: Kontexte - Formen - Wirkungen (pp. 67-83). Ergon-Verlag.

Winkelman, M. J. (2013b). Shamanism and psychedelics: A biogenetic structuralist paradigm of ecopsychology. European Journal of Ecopsychology, 4, 90-115.

Winkelman, M. J. (2014). Political and demographic-ecological determinants of institutionalised human sacrifice. Anthropological Forum, 24(1), 47-70.

Winkelman, M. J. (2015). Shamanism as a biogenetic structural paradigm for humans' evolved social psychology. Psychology of Religion and Spirituality, 7(4), 267-277. https://doi.org/10.1037/rel0000034.

Winkelman, M. J. (2017a). Shamanism and the brain. In N. K. Clements (Ed.), Religion: Mental religion (pp. 355-372). Handbooks MacMillan Publishers.

Winkelman, M. J. (2017b). Mechanisms of psychedelic visionary experiences: Hypotheses from evolutionary psychology. Frontiers in Neuroscience, 11, 539. https://doi.org/10.3389/fnins.2017.00539.

Winkelman, M. (2018). Shamanism and possession. In H. Callan (Ed.), The international encyclopedia of anthropology. Wiley Online Library. https://doi.org/10.1002/9781118924396.wbiea1651.

Winkelman, M. J. (2019a). The evolutionary origins of the supernatural in ritual behaviours. In P. Craffert, J. Baker, \& M. J. Winkelman (Eds.), The supernatural after the neuro-turn (pp. 48-68). Routledge.

Winkelman, M. J. (2019b). The supernatural as innate cognitive operators. In P. Craffert, J. Baker, \& M. J. Winkelman (Eds.), The supernatural after the neuro-turn (pp. 89-106). Routledge.

Winkelman, M. J. (2019c). Shamanic alterations of consciousness as sources of supernatural experiences. In P. Craffert, J. Baker, \& M. J. Winkelman (Eds.), The supernatural after the neuro-turn (pp. 127-147). Routledge.

Winkelman, M. (2021). The evolved psychology of psychedelic set and setting: Inferences regarding the roles of shamanism and entheogenic ecopsychology. Frontiers in Pharmacology, 12, 619890. https://doi.org/ 10.3389/fphar.2021.619890.

Winkelman, M. J., \& Baker, J. (2016). Supernatural as natural. Routledge.

Winkelman, M. J., \& White, D. (1987). A cross-cultural study of magico-religious practitioners and trance states: Data base. In D. Levinson \& R. Wagner (Eds.), Human relations area files research series in quantitative cross-cultural data (Vol. 3, pp. i-106). HRAF Press.

Winter, J. (2000). Tobacco use by Native North Americans : sacred smoke and silent killer. University of Oklahoma.

Publisher's Note Springer Nature remains neutral with regard to jurisdictional claims in published maps and institutional affiliations.

\section{Affiliations}

\section{Michael James Winkelman ${ }^{1,2}$}

1 School of Human Evolution and Social Change, Arizona State University, Tempe, AZ, USA

2 Pirenópolis, Brazil 